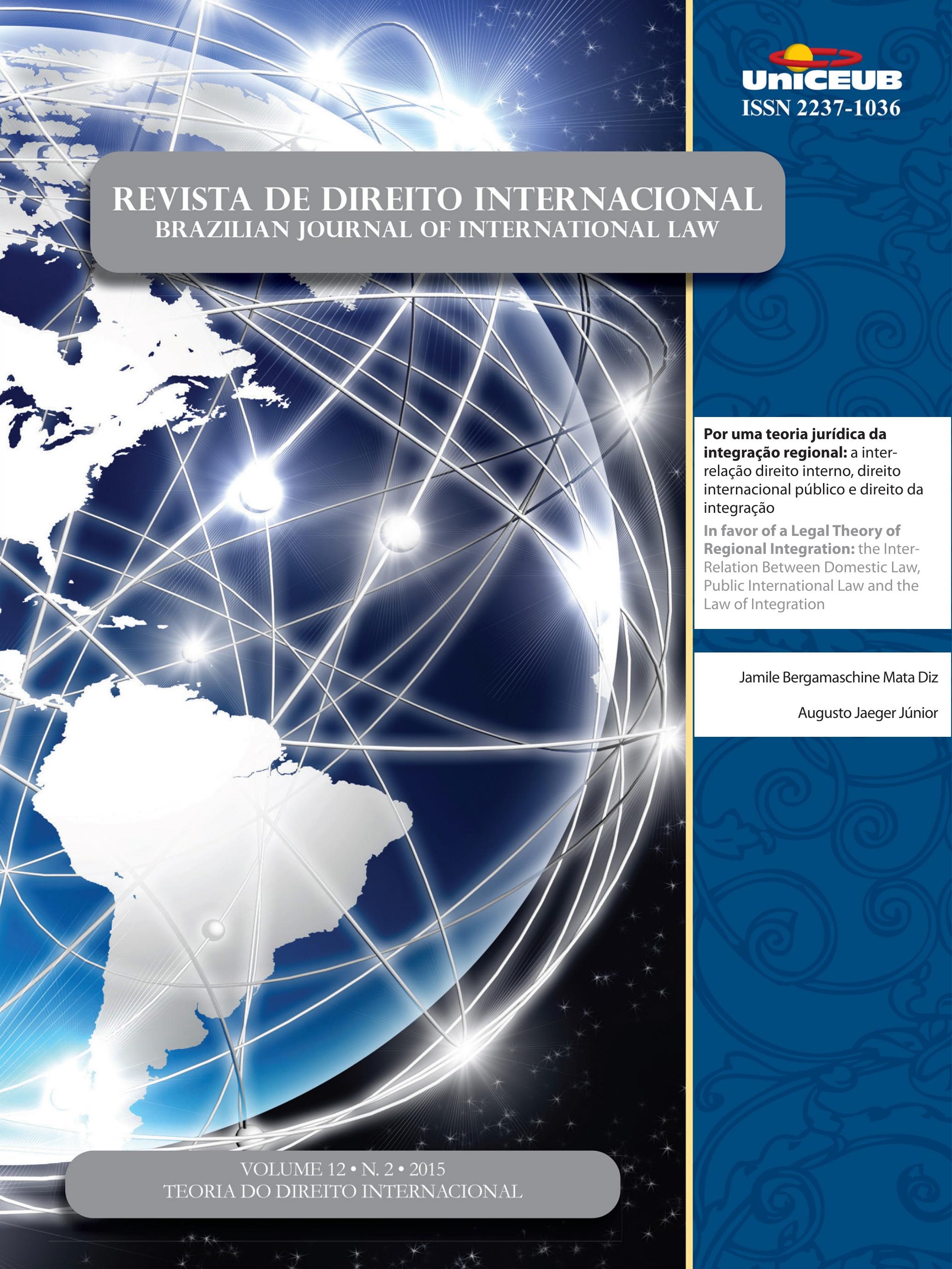




\section{Sumário}

CrôNiCAS DA ATUALIDADE do DiREITo INTERnACIONAL ..................................................... 2 Sarah Dayanna Lacerda Martins Lima, Carina Costa de Oliveira e Erika Braga

CrôniCas do Direito InternaCional dos InVESTIMENTOS ..............................................12 Nitish Monebhurrun

Por que voltar a Kelsen, o jurista do século XX ? 16 Inocêncio Mártires Coelho

O Princípio da Efetividade como conteúdo da norma fundamental (GrundNorm) DE KELSEN

Carlos Alberto Simões de Tomaz e Renata Mantovani de Lima

A JURIDIFICAÇÃo DE CONFLITOS POLÍTICOS NO DIREITO INTERNACIONAL PÚBLICO CONTEMPORÂ-

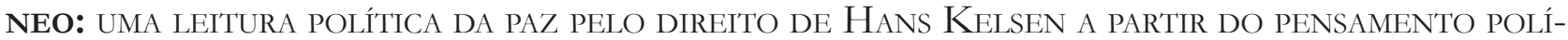
TICO De Claude Lefort

Arthur Roberto Capella Giannattasio

O SINCRETISMO TEÓRICO NA APROPRIAÇÃO DAS TEORIAS MONISTA E DUALISTA E SUA QUESTIONÁVEL UTILIDADE COMO CRITÉRIO PARA A CLASSIFICAÇÃO DO MODELO BRASILEIRO DE INCORPORA-

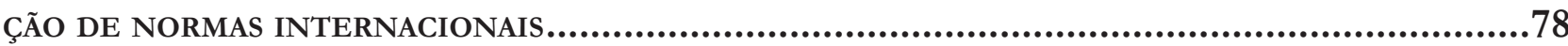
Breno Baía Magalhães

Direito Global em Pedaços: Fragmentação, Regimes e Pluralismo .98 Salem Hikmat Nasser

Por uma TeOria JURÍdica da INTEGRaÇão REgIONAL: A INTER-RELAÇÃO DiREITO INTERNO, DiREITO INTERNACIONAL PÚBLICO E DIREITO DA INTEGRAÇÃO Jamile Bergamaschine Mata Diz e Augusto Jaeger Júnior

A teOria DA INTERCONSTITUCIONALIDADE: UMA ANÁlISE COM BASE NA AMÉRICA LATINA...........160 Daniela Menengoti Ribeiro e Malu Romancini 
O DIÁLOGO HERMENÊUTICO E A PERGUNTA ADEQUADA À APLICAÇÃo DOS TRATADOS INTERNACIONAIS DE DIREITOS HUMANOS NO BRASIL: CAMINHOS PARA O PROCESSO DE INTERNACIONALIZAÇÃO

DA CONSTITUIÇÃO...................................................................................... 176

Rafael Fonseca Ferreira e Celine Barreto Anadon

O DIREITO COMPARADO NO STF: INTERNACIONALIZAÇÃO DA JURISDIÇÃO CONSTITUCIONAL BRASILEIRA

Carlos Bastide Horbach

THE PHILOSOPHY OF INTERNATIONAL LAW IN CONTEMPORARY SCHOLARSHIP: OVERCOMING NE-

GLIGENCE THROUGH THE GLOBAL EXPANSION OF HUMAN RIGHTS

Fabrício Bertini Pasquot Polido, Lucas Costa dos Anjos e Vinícius Machado Calixto

OpORTUNIDADES E DESAFIOS DAS TWAIL NO CONTEXTO LATINO-AMERICANO A PARTIR DE PERSPECTIVAS DOS POVOS INDÍGENAS AO DIREITO INTERNACIONAL

Fernanda Cristina de Oliveira Franco

Por Que uma ANÁlise ECONÔMICA Do DIREITO INTERNACIONAL PÚBLICO? DESAFIOS E PERSPECTIVAS DO MÉTODO NO BRASII

Gustavo Ferreira Ribeiro e Jose Guilherme Moreno Caiado

ANÁliSE ECONÔMICA do DIREITO INTERNACIONAL .263 Michele Alessandra Hastreiter e Luís Alexandre Carta Winter

RACIONALIDADE ECONÔMICA E OS ACORDOS BILATERAIS DE INVESTIMENTO 284 Michele Alessandra Hastreiter e Luís Alexandre Carta Winter

LOOKING FOR A BRICS PERSPECTIVE ON INTERNATIONAL LAW .304 Gabriel Webber Ziero

A INFLUÊNCIA DO DIREITO DESPORTIVO TRANSNACIONAL NO ORDENAMENTO JURÍDICO BRASILEIRO: DA REPRODUÇÃO DE NORMAS À APLICAÇÃO DIRETA PELA JURISDIÇÃO ESTATAL.......................3324 Tiago Silveira de Faria

CONVENCIONALIZAÇÃo DO DIREITO CIVIL: A APLICAÇÃo DOS TRATADOS E CONVENÇÕES INTERNACIONAIS NO ÂMBITO DAS RELAÇÕES PRIVADAS . 
NATIONAL JUdGES AND COURTS AS INSTITUTIONS FOR GLOBAL ECONOMIC GOVERNANCE 356

Juízes e tribunais nacionais como instituições para a governança global 356 Camilla Capucio

Is Trade Governance Changing? 371 Alberto do Amaral Júnior

OS FUNDOS ABUTRES: MEROS PARTICIPANTES DO CENÁRIO INTERNACIONAL OU SUJEITOS PERANTE O DIREITO INTERNACIONAL? 384

Guilherme Berger Schmitt

SHAREHOLDER AGREEMENTS IN PUBLICLY TRADED COMPANIES: A COMPARISON BETWEEN THE

U.S. AND BRAZIL. 402 Helena Masullo

REgulaÇÃo DO INVESTIMENTO ESTRANGEIRO DIRETO NO BRASIL: DA RESISTÊNCIA AOS TRATADOS BILATERAIS DE INVESTIMENTO À EMERGÊNCIA DE UM NOVO MODELO REGULATÓRIO 421 Fabio Morosini e Ely Caetano Xavier Júnior

DA QUALIFICAÇÃo JURÍDiCA dAS Distintas FORMAS DE PRESTAÇão TECNOLÓGICA: BREVE ANÁLISE DO MARCO REGULATÓRIO INTERNACIONAL

Daniel Amin Ferraz

REDEFINING TERRORISM: THE DANGER OF MISUNDERSTANDING THE MODERN WORLD'S GRAVEST THREAT

Jennifer Breedon

As EXECUÇões SELETIVAS E A RESPONSABILIZAÇÃo DE AGENTES TERRORISTAS 485 Alexandre Guerreiro

INTERNATIONAL CRIMINALS AND THEIR VIRTUAL CURRENCIES: THE NEED FOR AN INTERNATIONAL EFFORT IN REGULATING VIRTUAL CURRENCIES AND COMBATING CYBER CRIME Joy Marie Virga

Criminalidad transnacional organizada en el Ámbito del MERCOSUR: ¿Hacia un Derecho Penal Regional?. .528 Nicolás Santiago Cordini e Mariano Javier Hoet 
RUMO À INTERNACIONALIZAÇÃo DA PROTEÇÃO PENAL DO MEIO AMBIENTE: DOS ECOCRIMES AO ECOCÍDIO

Kathia Martin-Chenut, Laurent Neyret e Camila Perruso

Engaging the U.N. Guiding Principles on Business and Human Rights: the inter-AMERICAN COMMISSION ON HUMAN RIGHTS \& THE EXTRACTIVE SECTOR 571 Cindy S. Woods

O DIREITO HUMANO À COMUNICAÇÃo PRÉVIA E PORMENORIZADA DAS ACUSAÇÕES NOS PROCESSOS administrativos: O desprezo do Superior Tribunal de Justiça ao Pacto de San José da Costa Rica e À Corte Interamericana de Direitos Humanos .590

Daniel Wunder Hachem e Eloi Pethechust

A responsabilidade internacional do Brasil em FaCe do CONTRole de ConVENCionaliDADE EM SEDE DE DIREITOS HUMANOS: CONFLITO DE INTERPRETAÇÃO ENTRE A JURISDIÇÃO DA Corte Interamericana de Direitos Humanos e o Supremo Tribunal Federal quanto a LEI DE ANISTIA 612

Carla Ribeiro Volpini Silva e Bruno Wanderley Junior

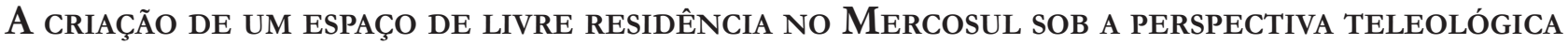
DA INTEGRAÇÃo REGIONAL: ASPECTOS NORMATIVOS E SOCIAIS DOS ACORDOS DE RESIDÊNCIA ....... 631

Aline Beltrame de Moura

A funcionalização como tendênCia evolutiva do Direito Internacional e sua conTRIBUIÇÃO AO REGIME LEGAL DO BANCO DE DADOS DE IDENTIFICAÇÃO DE PERFIL GENÉTICO NO BRASIL

Antonio Henrique Graciano Suxberger

O DIREITO INTERNACIONAL E A PROTEÇÃO DOS DIREITOS DE CRIANÇAS E DE ADOLESCENTES EM CONFLITO COM A LEI EM MOÇAMBIQUE

Bernardo Fernando Sicoche

ObTenÇão de PRovas no EXTERIOR: PARA ALÉM dA LEX FORI E LEX DiLigENTIAE. .685 André De Carvalho Ramos 
A Slight Revenge and a Growing Hope for Mauritius and the Chagossians: The UNClos Arbitral Tribunal's Award of 18 March 2015 on Chagos Marine Protected Area (Mauritius v. United Kingdom)

Géraldine Giraudeau

ANÁLISE DA RESPONSABILIDADE INTERNACIONAL DA UCRÂNIA POR VIOLAÇÃo DOS DIREITOS HUmanos na QUeda do voo da Malaysia Airlines (MH17). .728

Daniela Copetti Cravo

NatureZa JURÍdica do DESENVOLVIMENTO SUSTENTÁVEL No DIREITO INTERNACIONAL ........739 Pedro Ivo Diniz

A INFLUÊNCIA Da SOFT LAW NA FORMaÇão do DiREITo AMBIENTAL .767 Leonardo da Rocha de Souza e Margareth Anne Leister

As COMPLICADAS INTER-RELAÇÕES ENTRE OS SISTEMAS INTERNOS E INTERNACIONAIS DE PROTEÇãO DO DIREITO AO MEIO AMBIENTE SADIO. 785 José Adércio Leite Sampaio e Beatriz Souza Costa 


\title{
Por uma teoria jurídica da integração regional: a inter-relação direito interno, direito internacional público e direito da integração*
}

\author{
In favor of a Legal Theory of Regional \\ Integration: the Inter-Relation Between \\ Domestic Law, Public International Law and the \\ Law of Integration
}

Jamile Bergamaschine Mata Diz**

Augusto Jaeger Júnior***

\section{Resumo}

As relações derivadas do processo de integração regional serão analisadas no presente artigo com base na necessidade de formular uma teoria jurídica própria que possa explicar o fenômeno da integração do ponto de vista de método, objeto e fontes próprios. Nesse sentido, o objetivo do presente trabalho será investigar em que medida pode-se determinar a existência de um método específico, de fontes próprias e autônomas, de um objeto predeterminado e de destinatários também singulares que possibilitem verificar a construção e o desenvolvimento de uma teoria jurídica diferenciada dos parâmetros já estabelecidos pelo direito internacional de corte clássico, dado que a análise da integração regional não pode se subjugar aos postulados de um Direito que não explica adequadamente essas novas conformações e blocos. A metodologia utilizada ancorou-se, principalmente, no método indutivo, já que este artigo parte do exame das premissas necessárias para formular uma teoria jurídica da integração fundada na defesa de uma autonomia que o tema merece receber. Conclui-se que o direito da integração utiliza-se dos métodos tradicionais de estudo e pesquisa, bem como de interpretação, ainda que sua aplicação se configure de forma diferenciada, dada a existência de fontes próprias e autônomas. O objeto próprio como elemento da teoria vinculada à presença dos atores estatais também pode ser verificado, especialmente quando analisamos a nova roupagem assumida pelos elementos constitutivos do Estado, com base nas modificações trazidas pela integração regional.

Palavras-chaves: teoria jurídica; direito da integração; direito internacional; União Europeia; Mercosul.

*** Professor Associado da Faculdade de Direito da UFRGS, em Porto Alegre, Brasil, onde leciona as disciplinas de Direito Comunitário e da Integração, Direito Internacional Privado e Direito Internacional Público para a graduação e para a pós-graduação. Bolsista de produtividade em pesquisa do CNPq, Doutor em Direito Comunitário da Concorrência pela UFRGS e Mestre em Direito Internacional pela UFSC. Email: augusto.jaeger@ufrgs.br

\section{Abstract}

The relations derived from the regional integration process are analyzed in this article from the need to formulate its own legal theory that can explain the phenomenon of integration from the point of view of the method, 
object and own sources. In this sense, the objective of this study is to investigate to what extent can determine the existence of a specific method, its own and autonomous sources of a predetermined object and also individual recipients that allow verify the construction and development of a different legal theory of the parameters established by international law classic cut, given that the analysis of regional integration can not subdue the postulates of a right which does not adequately explain these new shapes and blocks. The methodology is anchored mainly on the inductive method, as this study is examining the assumptions necessary to formulate a legal theory of integration based on the defense of autonomy that the subject deserves. We conclude that the right of integration is used from traditional methods of study and research as well as interpretation, although its application is set differently given the existence of own and autonomous sources; the object itself as a theory element linked to the presence of state actors can also be checked, especially when we analyze the new look assumed by the constituent elements of the state, from the changes brought about by regional integration.

Keywords: legal theory; integration law; international law; European Union; Mercosur

\section{INTRODUÇÃo}

A integração regional entendida como a formação de processos de associação interestatais com a finalidade de conformar um sistema comum mediante a convergência de interesses e valores sempre foi objeto de atenção por parte da sociedade e dos acadêmicos das mais diversas áreas. Como tema específico vinculado ao direito internacional, foi pouco a pouco ganhando expressão no âmbito universitário até conformar-se como disciplina autônoma, já que ostenta objeto, métodos e fontes próprios, além de fundamentar-se sobre pressupostos independentes daqueles aplicados pelo direito internacional, conforme será analisado.

A criação de uma comunidade de países que compartam interesses e valores comuns demanda uma análise específica, voltada para o entendimento de questões que não são necessariamente tratadas pelo direito internacional clássico, especialmente quando essa comunidade adota também um sistema normativo e institucional próprio, em que o processo de tomada de decisões realize-se por um esquema completamente diferenciado dos modelos tradicionais existentes, baseados no sistema estatal e, ainda, em que os elementos clássicos da formação do Estado experimentem modificações substanciais, especialmente no que tange ao compartilhamento ou à transferência do exercício de poderes e competências estatais.

A justificativa para o presente trabalho pode ser referendada não somente pela crescente e complexa dimensão da integração regional, merecedora, sem dúvida, de uma teoria própria e autônoma, mas, também, pelo crescente domínio do direito da integração sobre o direito interno.

No momento atual, quando se fala de uma crise da integração à raiz dos problemas gregos, quando alguns anunciam o fim da União Europeia, quando se fala num Mercosul natimorto, quando se questiona a atuação das instituições comunitárias andinas... torna-se importante debruçar-se ainda com maior afinco ao tema, não em vã e estéril tentativa de alçá-lo a uma espécie de redenção e libertação dos fatores políticos e econômicos, mas ao contrário, para entender a integração com base em uma perspectiva jurídica sem isolá-la dos demais aspectos que a compõem; para entender como esse tipo de associação entre Estados resulta numa abordagem diferenciada dos padrões tradicionais; e para defender que a análise da integração regional não possa se subjugar aos postulados de um Direito que não explica, adequadamente, essas novas conformações e blocos. Portanto, o objetivo do presente trabalho será analisar como a integração regional demanda um estudo que leve em consideração as especificidades do processo de associação entre Estados tendentes a conformar um sistema institucional e normativo próprio, diferenciado das organizações internacionais clássicas. O exame se centrará nos elementos teóricos que possam fixar a autonomia do direito da integração face ao direito internacional, devendo o método, o objeto e as fontes constituírem os aspectos principais para que a teoria possa ser formulada. Ainda, os processos de integração analisados serão a União Europeia por encontrar-se em uma etapa mais avançada de integração ao constituir uma união econômica e monetária, e o Mercosul, que conta com a participação do Brasil como Estado-Parte. Portanto, o recorte feito para englobar somente estes dois processos de integração vincula-se ao desenvolvimento das etapas integracionistas conhecidas por ambos os processos. 
A metodologia de trabalho deverá centrar-se nos aspectos principais estabelecidos para uma pesquisa interdisciplinar que envolva temas de direito da integração e de direito internacional, devido, especialmente, ao caráter específico e singular que deve estar presente em toda análise de um sistema jurídico próprio aplicado a um determinado tipo de relação interestatal, como é o caso da formação de processos de integração regional. Nesse sentido, devem-se utilizar métodos que permitam analisar a evolução e desenvolvimento do direito da integração. Os métodos histórico e indutivo permitirão estabelecer as premissas conceituais e práticas aplicadas ao tema escolhido, já que possibilitam os parâmetros necessários para compreender um fenômeno típico do século XX, dado que a análise histórica da integração regional nos permite uma devida compreensão do modo e meio de desenvolvimento dos processos em curso ao reforçar os pontos de contato com os momentos vividos por cada um deles (em especial a União Europeia). A indução parte de um exame das premissas necessárias para formular uma teoria jurídica da integração ancorada na defesa de uma autonomia que o tema merece receber.

\section{A QUESTÃO DO MÉTOdO COMO FUNDAMENTO DA TEORIA: HÁ, EFETIVAMENTE, A NECESSIDADE DE CRIAR SISTEMAS METODOLÓGICOS PRÓPRIOS?}

De início, pode-se afirmar que os estudiosos do Direito aplicam procedimentos e técnicas metodológicas que são empregadas indistintamente a todos os ramos do conhecimento jurídico. A aplicação de métodos de abordagem $^{1}$ de estudo e pesquisa pode dar-se, como no caso das ciências sociais aplicadas, de forma a abarcar uma concepção indutiva, dedutiva, hipótetico-dedutiva, entre outra ${ }^{2}$. Também há métodos tradicionalmente reconhecidos, utilizados para a interpretação dos sistemas jurídicos, tanto de natureza interna como internacional, como é o caso do método teleológico, sistemático e

1 Lakatos e Marconi fazem diferença entre métodos de abordagem e métodos de procedimento, considerando estes últimos como etapas mais concretas de investigação, classificando-os, inclusive, mais como técnica que como método. LAKATOS, Eva Maria; MARCONI, Mariana de Andrade. Fundamentos de metodologia científica: Técnicas de pesquisa. 3 ed. São Paulo: Atlas, 2003.

2 LAKATOS, Eva Maria; MARCONI, Mariana de Andrade. Fundamentos de metodologia científica: Técnicas de pesquisa. 3 ed. São Paulo: Atlas, 2003. gramatical. Neste trabalho, pretende-se realizar uma primeira aproximação aos métodos de estudo e pesquisa que podem ser aplicados ao estudo da integração, dada sua especificidade, bem como aos métodos interpretativos que podem ser utilizados pelo direito da integração, de modo a examinar se haveria ou não a necessidade de criação de métodos próprios completamente diferenciados dos métodos tradicionais, ou se, ao contrário, o que se deve determinar é uma aplicação diferenciada destes.

Os métodos de estudo e pesquisa usualmente empregados na pesquisa em ciências sociais aplicadas são aqui considerados com base no marco teórico apresentado por Lakatos e Marconi, e que podem ser assim sintetizados:

- método indutivo: parte-se de uma premissa menor já cientificamente constatada para uma premissa maior, de modo que "partindo de dados particulares, suficientemente constatados, infere-se uma verdade geral ou universal, não contida nas partes examinadas."

- Método dedutivo: nesse caso, parte-se de uma premissa maior que pode ser, inclusive, capturada da realidade social para que se possa explicar o conteúdo das premissas, de modo a gerar formulações baseadas na certeza. Ainda na esteira de Lakatos e Marconi, os "argumentos indutivos aumentam o conteúdo das premissas, com sacrifício da precisão, ao passo que os argumentos dedutivos sacrificam a ampliação do conteúdo para atingir a certeza"4.

- Método hipótetico-dedutivo: ancorado na análise de Popper ${ }^{5}$, esse método propõe a verificação com base em um problema, que seria testado por uma teoria-tentativa para posteriormente criticar a solução, num esquema de tentativa-erro, de forma a eliminar as possíveis incorreções.

A aplicação desses métodos na pesquisa e no estudo em direito internacional pode ser inferida com base nos estudos apresentados pelos internacionalistas (cite-se, a título de exemplo, Schwarzenberger $\left.{ }^{6}\right)$, preocupados em

3 LAKATOS, Eva Maria; MARCONI, Mariana de Andrade. Fundamentos de metodologia científica: Técnicas de pesquisa. 3 ed. São Paulo: Atlas, 2003, p. 85.

4 LAKATOS, Eva Maria; MARCONI, Mariana de Andrade. Fundamentos de metodologia científica: Técnicas de pesquisa. 3 ed. São Paulo: Atlas, 2003, p. 92.

5 POPPER, Karl S. A lógica da pesquisa cientlfica. 2. ed. São Paulo: Cultrix, 1975.

6 SCHWARZENBERGER, Georg. International Law, Vol. I, second edition, London, 1949 apud RANGEL, Vicente Marotta. 
destacar a importância do método como instrumento essencial para a explicação dos problemas derivados pelo direito das gentes. Nesse sentido, entende Rangel ${ }^{7}$ ao abordar os métodos dedutivos e indutivos como consagradamente "adotados" pelo direito internacional, pois "amplamente difundidos, conhecem-se argumentos favoráveis a um e outro método tanto quanto os inconvenientes que a adoção exclusiva de um deles acarreta", defendendo uma aplicação simultânea de ambos os métodos, ainda que acabe por ocorrer a prevalência de um deles.

Rangel aponta ainda que "O problema que estamos a considerar oferece peculiaridades no que tange à pesquisa $\mathrm{e}$ ao ensino do direito das gentes. Deles emanam dificuldades precisas." ". Nesse sentido, dois aspectos interessantes são mencionados pelo autor, o primeiro se refere ao influxo das questões de política internacional sobre o Direito e o segundo se vincula à propagação do domínio internacional sobre as políticas internas, dado que

a área de aplicação do direito internacional penetra, de forma progressiva, em setores que tradicionalmente eram reservados ao direito interno dos Estados. Ela o faz de maneira envolvente à medida que se atenuam as rígidas barreiras outrora erguidas entre os dois ordenamentos jurídicos ${ }^{9}$.

Os problemas derivados da aplicação de métodos tradicionais ao estudo da integração — partindo-se da consideração que os mesmos também não podem ser ab initio aplicados indiscriminadamente ao direito internacional, conforme apontado alhures — se vinculam notadamente às modificações trazidas pela integração no que tange à formação de um sistema institucional e normativo próprio, distinto daqueles sistemas que foram ao longo do tempo criados pelo direito internacional. Fácil é observar que o estudo do funcionamento de uma organização internacional clássica, como é o caso das Organizações das Nações Unidas (ONU), não pode ser completamente semelhante ao estudo de uma organização de integração, como é o caso da União Europeia, dada uma das características principais deste tipo organizacional, que é a transferência de poderes e competências em dimensão mais alargada da que até

Direito e Relações internacionais. $2^{a}$. Ed. São Paulo: Editora RT. 1981, p. 273.

7 RANGEL, Vicente Marotta. Direito e Relações internacionais. 2a. Ed. São Paulo: Editora RT. 1981, p. 273.

8 RANGEL, Vicente Marotta. Direito e Relações internacionais. 2a. Ed. São Paulo: Editora RT. 1981, p. 275.

9 RANGEL, Vicente Marotta. Direito e Relações internacionais. $2^{a}$. Ed. São Paulo: Editora RT. 1981, p. 276. então vinha sendo outorgada às organizações internacionais. Ao possibilitar aos Estados-membros que as instituições nascidas com base nessa organização possam decidir — em e para os próprios Estados — sobre as políticas públicas que hão de se aplicar internamente, o funcionamento destas (por exemplo, no que tange ao peso e ponderação de votos ou a formação de maiorias simples, absolutas ou relativas) não pode ser compreendido com base na clássica concepção adotada pelo direito internacional, apesar das dificuldades encontradas pelos teóricos para vislumbrar pontos de semelhança entre o direito da UE e outros sistemas, conforme apontam Cryer et all ${ }^{10}$ :

Walkers indaga se a legislação da UE exige novas ferramentas de análise e nova forma de construção teórica, e nós concordamos que é uma pergunta que vale a pena explorar ( ... . . Se a legislação da UE deve ser abordada com uma nova compreensão teórica e metodológica própria, deve-se questionar se a roda precisa ser reinventada, e ao descrever a UE como um sistema sui generis não responde à questão em que medida ela se assemelha a outro sistema (...).

O método adotado para o estudo da integração não pode ser aplicado, portanto, de modo idêntico àquele utilizado para o direito internacional. A especificidade do método reside, justamente, na conformação diferenciada trazida por um mercado comum ou interno e pode ser explicada com base nas questões vinculadas, por exemplo, à vigência simultânea ou à incorporação imediata das normas do bloco, sem que haja, necessariamente, a criação de órgãos e instituições supranacionais, como é o caso do Mercosul.

Além disso, a própria questão da supranacionalidade, que será verificada posteriormente neste artigo, demanda uma sistemática metodológica diferenciada que não pode ser, de forma direta e imediata, trasladada ao plano do direito da integração.

Contudo, não se nega neste artigo que o método de pesquisa usado para compreender o fenômeno da in-

10 No original: Walkers wonders whether EU law requires its own new tools of analysis and new form of theory building, and we agree that is a question worth exploring (...). If EU law is to be approached with an understanding of theroy and methodology, it must be questioned whether the wheel need to be reinvented, and to describe the EU as a sui generis system does not answer the question of in what it resembles other system, or amounts to a theorical shrug of the shoulders when it comes dealing with insights from other areas of study. CRYER, Robert, et all. Research methodologies in EU and International Law. Oxford and Portland: Hart Publishing, 2011, p. 20. 
tegração deva ser absolutamente distinto dos métodos tradicionais empregados pelo Direito, mas sim que deve haver uma aplicação específica que leve em consideração aspectos intrínsecos dos processos de integração regional, sem descuidar o caráter inovador de alguns destes aspectos, conforme será abordado posteriormente neste trabalho. Tal aplicação específica significa que os métodos considerados tradicionais pela ciência jurídica devem adaptar-se ou até mesmo amoldar-se à nova realidade criada pelos espaços interestatais de associação, como é o caso da União Europeia e do Mercosul. Nesse mesmo sentido, expressa López ${ }^{11}$ :

a construção europeia, agora referida especificamente à UE, é uma nova realidade; mais especificamente, podemos definir como um processo dinâmico (e inacabado) a criação de um novo espaço territorial a partir do direito, a partir dos direitos, dos EstadosMembros. A supraestatalidade é a própria essência da União e o dado crucial em que reside a novidade que nos obriga a ajustar a metodologia. Do ponto de vista da teoria de fontes se aprecia claramente este fato, se falamos sobre a complexidade ordinamental, a existência de diferentes sistemas em uma mesma área de validade territorial. Realmente a experiência europeia poderia remeter-se para o direito constitucional do federalismo, mas sua própria singularidade não permite uma transposição perfeita de categorias.

O autor afirma que

certamente já começa a tornar-se evidente que esta nova realidade exige novos princípios, uma metodologia até então inexplorada. E não pode ser de outra forma, por duas razões: a diversidade de tradições de partida e pioneirismo de seu objeto. Desta síntese resulta um novo corpo em que há partes, entre outros, do direito alemão, do francês e do britânico. ${ }^{12}$

11 No original: La construcción europea, referida ahora específicamente a la UE, es una nueva realidad; más concretamente la podemos definir como un proceso dinámico (e inacabado) de creación de un nuevo espacio territorial a partir del derecho, a partir de los derechos, de los Estados miembros. La supraestatalidad es la verdadera esencia de la Unión y el dato crucial en el que radica la novedad que nos obliga a ajustar la metodología. Desde el punto de vista de la teoría de las fuentes se aprecia con toda claridad este hecho si hablamos de la complejidad ordinamental, de la existencia de diferentes ordenamientos en un mismo ámbito de validez territorial. Realmente la experiencia europea podría remitirse al Derecho constitucional del federalismo pero su misma singularidad no permite hacer una transposición perfecta de categorías. LOPEZ, Enrique Guillen. Metodología del Derecho Constitucional Europeo: Un derecho Constitucional para la integración política de Europa. Del pluralismo ideológico. Revista de Derecho Constitucional Europeo, n. 12, UGR, 2009, p. 154.

12 No original: Ciertamente ya comienza a hacerse evidente que esta nueva realidad requiere principios nuevos, una metodología hasta ahora inexplorada. Y no puede ser de otro modo por dos ra-
Para que se possa efetivamente fixar as bases - ainda que sem pretensão de esgotar o tema, dada a complexidade do mesmo — de métodos que podem ser utilizados para o estudo e pesquisa da integração interestatal, deve-se, primeiramente, em breve aproximação, definir quais são os principais métodos atualmente aplicados no estudo da integração. De modo geral, considera-se que a abordagem metodológica tradicionalmente empregada pelos estudiosos do direito internacional vem sendo amplamente replicada nos estudos da integração, conforme ressalta López. ${ }^{13}$

Portanto, faz-se necessário defender que se pode fixar como métodos de abordagem aqueles já utilizados pelas ciências sociais aplicadas de modo geral e, especificamente, para o estudo e a pesquisa em Direito, mas que, no caso da integração regional, deve ser adaptado de forma que permita abarcar as inovações trazidas pelo direito da integração, notadamente a institucionalidade e normatividade trazidas por esse tipo de associação interestatal. A adaptação defendida neste artigo deve ser compreendida como um esforço do pesquisador em estabelecer as premissas que surgem do direito da integração, ainda que enraizadas no direito internacional, segundo será posteriormente investigado.

No que tange aos métodos interpretativos, em geral, os autores mencionam a interpretação teleológica-axiológica entendida como aquela que "ativa a participação do intérprete na configuração do sentido. Seu movimento interpretativo, inversamente da interpretação sistemática que também postula uma cabal e coerente unidade do sistema, parte das consequências avaliadas das normas e retorna para o interior do sistema"14; a interpretação sistemática considerada como processo que "a partir do sistema externo da lei, portanto nas conclusões retiradas da localização de um preceito em determinado livro, seção ou conexão de parágrafos, da

zones: la diversidad de las tradiciones de partida y lo pionero de su objeto. De la síntesis resulta un nuevo cuerpo en el que hay piezas, entre otros, del derecho alemán, del francés y del británico. LOPEZ, Enrique Guillen. Metodología del Derecho Constitucional Europeo: Un derecho Constitucional para la integración política de Europa. Del pluralismo ideológico. Revista de Derecho Constitucional Europeo, n. 12, UGR, 2009, p. 156.

13 LOPEZ, Enrique Guillen. Metodología del Derecho Constitucional Europeo: Un derecho Constitucional para la integración política de Europa. Del pluralismo ideológico. Revista de Derecho Constitucional Europeo, n. 12, UGR, 2009, p. 156

14 FERRAZ JÚNIOR, Tércio Sampaio. Introdução ao Estudo do Direito: técnica, decisão, dominação. $6^{a}$ ed. - São Paulo: Atlas, 2008, p. 266. 
sua configuração com proposição autônoma ou como mera parte de uma proposição" ${ }^{15}$, não podendo-se considerar um norma isolada de seu contexto normativo, atribuindo-lhe um sentido dentro de um sistema complexo; ainda apontam a interpretação gramatical e a interpretação histórica ${ }^{16}$.

Uma análise reducionista e tradicional dos métodos interpretativos aplicados tradicionalmente pelo Direito, enquanto ciência, não pode explicar como os Estados tendem a associar-se, formando uma institucionalidade distinta daquelas adotadas pelo direito internacional, através de suas organizações. Basicamente, a aplicação tradicional não permite, por exemplo, estabelecer em que medida e porque decidem os Estados transferir competências e poderes para uma organização supranacional.

Pois bem, para a compreensão de um método interpretativo de aplicação (e não de criação) para o direito da integração pode-se adotar um recorte singular a partir de distintas variáveis, entre elas: i) a análise dos sistemas normativos de integração com base em cada processo integrador; ii) a análise das decisões emanadas dos órgãos de solução de controvérsias naqueles processos de integração regional que contam com um sistema judicial próprio; iii) com base na atuação das instituições legislativas e da formação de um processo legislativo específico para a criação de normas comuns, entre outras.

De forma a validar a possibilidade do emprego de métodos interpretativos tradicionais, mas aplicados de forma diferenciada para o estudo do direito da integração, escolheu-se neste artigo a análise das decisões emanadas do Tribunal Arbitral do Mercosul, onde desponta, ainda que não exclusivamente, o uso do método teleológico e do método sistemático. No caso do método teleológico, ao analisar o primeiro laudo arbitral sob o Protocolo de Brasília ${ }^{17}$, I Laudo Arbitral, TADM, Mon-

15 CANARIS, Claus-Wilhelm. Pensamento Sistemático e Conceito de sistema na Ciência do Direito. $3^{\mathrm{a}}$ ed. - Lisboa: Fundação Calouste Gulbenkian, 2002, p. 158.

16 Não será feita no presente artigo uma análise aprofundada das questões relativas a todos os tipos e classificações dos métodos intepretativos, dado não ser o objetivo do mesmo. Contudo, recomenda-se a leitura de MAXIMILIANO, Carlos. Hermenêutica e aplicação do Direito. 19a ed. - Rio de Janeiro: Forense, 2002; BETTI, Emilio. Interpretação da Lei e dos atos jurídicos: teoria geral e dogmática. Trad.: Karina Janinni. $2^{\mathrm{a}}$ ed. - São Paulo: Martins Fontes, 2007; STRECK, Lenio Luiz. Hermenêutica Jurídica e(m) Crise. $10^{a}$. ed. Porto Alegre: Livraria do Advogado, 2010, entre outros.

17 Tratou-se de caso em que foi objetada uma norma brasileira que internalizou regras do Mercosul no ordenamento jurídico na- tevidéu, 28 de abril de 1999, a linha de argumentação seguida pelo Tribunal reconhece o papel central da liberação comercial no cumprimento dos fins e objetivos do Mercosul, a natureza inseparável das vertentes tarifária e não tarifária e a obrigação de eliminar totalmente as restrições em ambas, bem como os cinco Anexos do TA, congruentes com essa interpretação, contêm obrigações concretas e autoexequíveis, e nenhuma norma expressa derrogou a obrigação de proceder ao desmantelamento não tarifário, subsistindo o sistema do TA e as obrigações nascidas com ele, apesar de haver sofrido modificações, especialmente decorrentes da expiração do prazo originalmente pactado para o alcance do mercado comum. Essa seria a conclusão com base em uma interpretação harmônica do sistema, congruente e não contraditória com os fins e objetivos declarados e acordados pelas partes.

Em conclusão, decidiu o Tribunal que a controvérsia situava-se no conjunto normativo do Mercosul, que contra ele devia ser invocada uma incompatibilidade de um ordenamento nacional, que os instrumentos do processo de integração devem ser interpretados em forma teleológica, tendo em conta os fins, objetivos e princípios do sistema de integração, mesmo na ausência de normas de caráter supranacional, bem como que o TA e seu sistema normativo contêm disposições que fixam objetivos e princípios que estabelecem obrigações concretas para os Estados, entre as quais se inclui o programa de liberação comercial que deve ser completado tanto em relação às medidas tarifárias quanto às não tarifárias.

A necessidade de ser interpretado o Tratado de Assunção e a normativa do Mercosul funcional ou teleologicamente, enquanto mecanismo de integração, para desestimar medidas nacionais que sejam contrárias ao objetivo final neles estabelecidos foi uma constante encontrada nos laudos arbitrais, até o nono, que torna a esses métodos, como se lê no seu item 19. Esse laudo, IX Laudo Arbitral, TADM, Montevidéu, 4 de abril de 2003, por sinal, no item 26, apresenta um outro método, chamado lógico-sistemático, que prega o atendimento

cional, assim o Comunicado n. 37/97, que estabelecia e consolidava a lista de capítulos e produtos da Nomenclatura Comum do Mercosul sujeitos a licença não automática ou a licença automática com condições especiais. A alegação é que o Comunicado piorava e agravava as condições de acesso ao mercado brasileiro de produtos argentinos, estabelecendo medidas administrativas equivalentes a restrições. 
aos princípios do Mercosul de gradualismo, flexibilidade e equilíbrio, consagrados no preâmbulo do Tratado de Assunção, que deveriam presidir a progressiva concretização, através da normativa vinculadora emanada dos órgãos do Mercosul, dos enunciados programáticos e princípios gerais essencialmente encerrados no corpo do Tratado ${ }^{18}$.

Já a aplicação do método sistemático foi enfatizada na Primeira opinião consultiva ${ }^{19}$, OC n. 1/2007, TPR, Assunção, 3 de abril de 2007, com base nas inovações advindas com o Protocolo de Olivos. A pergunta abarcava, exclusivamente, questões atinentes à interpretação jurídica da normativa do Mercosul e se vinculava com causa que estivesse tramitando no Poder Judiciário do Estado-parte solicitante, com o que restavam cumpridas as exigências do Protocolo de Olivos para a submissão de opinião consultiva. Ainda, segundo o item A, 3, a aceitação da questão considerava a sua transcendental importância para assentar os sólidos cimentos do conceito, natureza e objetivo das opiniões consultivas dentro do processo de integração, dado o contexto da consulta, e segundo o item B, 1, a função do tribunal nos casos em tela consistia em interpretar a norma comunitária desde o ponto de vista jurídico, vale dizer, buscar o significado para precisar o seu alcance, ainda que uma opinião consultiva não seja obrigatória, nem vinculante para o juiz nacional consultante. No mesmo item, lembram os interpretadores que na União Europeia, um recurso semelhante é sempre vinculante.

No item C, 1, buscando resolver já a questão, o tribunal informa que "as três características básicas do então direito comunitário são: i) a aplicação imediata, ii) o efeito direto, iii) a prevalência normativa sobre o direito

18 JAEGER JUNIOR, Augusto. Metodologia jurídica europeia e mercosulista: considerações fundamentais. Revista da Secretaria do Tribunal Permanente de Revisão do Mercosul. Assunção: Secretaria do Tribunal Permanente de Revisão do Mercosul, a. 2, n. 3, mar. 2014. p. 117-157. Disponível em: http://www.revistastpr. com/index.php/rstpr/article/view/87/66, acesso em 13 mar 2015. 19 Em 2007, surgiu a primeira opinião consultiva do TPR. Uma juíza de primeira instância do cível e do comercial de primeiro grau da jurisdição de Assunção, Paraguai, via Corte Suprema de Justiça do Paraguai, em autos em que litigavam duas empresas privadas, a argentina Laboratorios Northia Sociedad Anónima e a paraguaia Norte Sociedad Anónima, endereçou uma questão ao TPR. Ela girava em torno da prevalência do Protocolo de Buenos Aires sobre Jurisdição Internacional em Matéria Contratual, uma norma integracionista, sobre uma lei nacional paraguaia, que determinava o devido respeito, por essa, à eleição de jurisdição contratualmente estabelecida entre as partes, em conformidade com o artigo $4^{\circ}$. de tal Protocolo, sustentando a primazia do tratado sobre a lei. interno", no momento em que cita o jurista espanhol Ricardo Alonso García e os seus comentários ao caso Costa/ENEL, do TJCE, de 1964, que determinou uma origem pretoriana aos preceitos acima, especialmente o terceiro. Para esse dissertante, pende novamente o TPR ao método comparativo. Evidentemente, o TPR tinha a oportunidade de uma criação também pretoriana para inseri-las dentro do regime jurídico e da metodologia jurídica mercosulistas.

Mais adiante, no item E, 4, que discutia a prevalência da norma de direito da integração sobre a ordem pública nacional e internacional, novamente a jurisprudência do TJCE é citada, em especial o caso Dieter Krombach, de 28 de março de $2000^{20}$.

$\mathrm{Na}$ sequência, antes de estimar a interpretação do articulado do Protocolo de Buenos Aires, informa o tribunal que este foi aprovado e ratificado por todos os Estados-partes do Mercosul, e que, por essa razão, estaria legitimado para angariar prevalência sobre a lei nacional de todos os Estados. E no mesmo item F, 3, informa que o Protocolo de Santa Maria, invocado no processo para ser aplicado, não o poderia ser, dado que, ainda, não se encontra em vigor. Essa conclusão é bastante simplória, mas muito representativa para a formação de uma metodologia jurídica mercosulista, especialmente porque reafirma que nem mesmo uma norma do Mercosul, em comparação com as normas do direito internacional público, não é dispensada do processo de ratificação pelos Estados-partes para que entre em vigor.

Então, no item E do voto do árbitro Nicolás Becerra, lê-se que "os Protocolos de Direito internacional privado são convenções internacionais, mas convenções muito particulares porque estão contidas em decisões do Mercosul - que têm caráter obrigatório segundo o Protocolo de Ouro Preto - e por terem sido adotadas no marco de um processo de integração. Esses dados são fundamentais no momento de fixar a interpretação de suas normas. É verdade que se tem que seguir o processo de incorporação previsto em cada Estado - dado que ainda não existe uma instância supranacional legiferante da que pudessem derivar normas como estas destinadas a sua aplicação direta nos países-membros -, mas uma vez em vigor essas convenções devem interpretar-se e aplicar-se em função das finalidades do Mercosul" e objetivos que os Estados-partes assumiram

20 STJCE, assunto Dieter Krombach v. André Bamberski, C-07/98, 28 de março de 2002. 
explícita e implicitamente ao adotarem tais normas, assim segundo um método nesse laudo chamado de interpretação sistemática, global.

Enfim, em conclusão, o TPR afirma que a cláusula atributiva de competência jurisdicional contida no contrato realizado entre as duas empresas confrontadas na lide era válida, posto que as normas do Mercosul internalizadas prevalecem sobre as normas do direito interno dos Estados-partes, sejam elas de direito interno propriamente dito ou de direito internacional público e privado, e, assim, o caso foi respondido pelo TPR muito mais pela elucidação do aparente conflito entre duas fontes normativas diversas aplicáveis, o Protocolo de Buenos Aires e uma lei nacional paraguaia, do que por uma real interpretação de uma norma do Mercosul ${ }^{21}$.

Percebe-se, portanto, que os métodos interpretativos podem ser aplicados ao estudo do direito da integração, contudo, devem considerar - ainda que não esteja exclusivamente apartada de uma concepção já amplamente adotada - as peculiariedades inerentes à normatividade gerada pelo processo integrador, justamente pelo reconhecimento das fontes jurídicas próprias emanadas do mesmo, tema que será abordado à continuação.

\section{As FONTES DO DIREITO DA INTEGRAÇÃO REGIO- NAL: UMA AUTONOMIA AINDA A SER DETERMINADA}

O reconhecimento de um direito da integração próprio e autônomo pode ser comprovado, ainda, pela coexistência de um sistema de fontes jurídicas, estabelecidas nos tratados constitutivos e cujo enunciado fixa quais serão os atos que servirão de sustento para o ordenamento jurídico integracionista. As características fornecidas pelas fontes servem como um elemento agregador para a afirmação da existência de um direito próprio, afastando-se das posições tradicionalistas que renegam a autonomia de dito direito. A peculiaridade do regime jurídico adotado pelos Estados para a formação da associação inter-regional acaba por implicar numa particular forma de produção normativa, em diferentes

21 JAEGER JUNIOR, Augusto. Metodologia jurídica europeia e mercosulista: considerações fundamentais. Revista da Secretaria do Tribunal Permanente de Revisão do Mercosul. Assunção: Secretaria do Tribunal Permanente de Revisão do Mercosul, a. 2, n. 3, mar. 2014. p. 117-157. Disponível em: http://www.revistastpr. com/index.php/rstpr/article/view/87/66, acesso em 13 mar 2015. âmbitos, que determinam aos Estados participantes um dever de cumprimento que, apesar de aceito por estes, pode ver-se debilitado, em maior ou menor medida, pela ausência dos mecanismos institucionais necessários (como é o caso do Mercosul). Não obstante, essa debilidade não resulta em negação expressa do direito da integração como um direito próprio, senão que reforça a falta de coercibilidade como premissa necessária que pode impedir o avanço do processo integrador a etapas mais profundas. Conforme ressaltado por Pallares,

os processos de integração têm como resultado a produção de normas legais para regular essas ações coletivas. Ao mesmo tempo, eles refletem um fluxo constante de interações entre Estados participantes e outros sujeitos destinatários de tais normas, e destacam o desenvolvimento de uma diversidade de funções próprias de verdadeiras estruturas orgânicas de natureza administrativa ${ }^{22}$.

A defesa de um direito do Mercosul próprio e autônomo já havia sido defendida, em 2004, ocasião em que afirmamos, na esteira de Perez Otermin ${ }^{23}$,

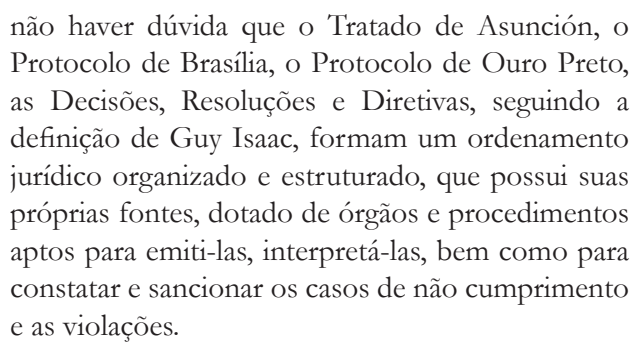

No mesmo sentido, o IX Laudo Arbitral, TADM, Montevidéu, 04 de abril de 2003, sobre medidas de Estímulo à industrialização de lã, utilizou a definição de

22 No original: Los procesos de integración tienen como resultado la producción de normas jurídicas destinadas a regular dichas acciones colectivas. $\mathrm{Al}$ mismo tiempo, reflejan un flujo permanente de interacciones entre los Estados participantes y otros sujetos destinatarios de tales normas y ponen de manifiesto el desarrollo de una diversidad de funciones propias de verdaderas estructuras orgánicas de índole administrativa. PALLARES, Beatriz y AGUZIN, Luiz. El régimen de incorporación de los tratados en el derecho interno. Congreso Internacional de Cultura y Sistemas jurídicos comparados. Instituto de Investigaciones Jurídicas. UNAM, México, 2004, p. 23, disponible em http://www.juridicas.unam.mx/inst/ evacad/eventos/2004/0902/mesa3/76s.pdf, acesso en 15 dec 2004 23 No original: no puede caber duda que el Tratado de Asunción, el Protocolo de Brasilia, el Protocolo de Ouro Preto, las Decisiones, Resoluciones y Directivas, siguiendo la definición de Guy Isaac, forman un ordenamiento jurídico organizado y estructurado, que posee sus propias fuentes, dotado de órganos y procedimientos aptos para emitirlas, interpretarlas, así como para constatar y sancionar los casos de incumplimiento y las violaciones. PEREZ OTERMÍN, Jorge. El Mercado Común del Sur. Desde Asunción a Ouro Preto: aspectos jurídico-institucionales. Montevideo: Fundación de Cultura Universitaria, 1995, p. 195. 
Isaac ${ }^{24}$ para afirmar a existência de um direito próprio, com um ordenamento jurídico individualizado.

A discussão sobre a validade do tratado como superior à norma de direito interno representa uma ligação intrínseca com a própria criação do então direito comunitário, embora não se possa ignorar que este representa um produto direto de uma determinada época e para uma determinada região, contudo, ao irradiar efeitos concretos e para além das fronteiras da UE, alcançou, num certo sentido, uma abrangência universal, isto é, apesar de aplicar-se diretamente aos membros e instituições da UE, pode, sim, alcançar relações que se formam fora do espaço europeu.

Nesse sentido, os princípios orientadores do processo de integração descritos nas linhas seguintes são importantes para a compreensão de como as fontes do direito, em um sistema integrado que envolve estados soberanos podem determinar o grau de cumprimento e a implementação do acervo normativo, considerando-se, especialmente, se este pertence ao direito interno ou se ancora-se numa formação supranacional ou até mesmo internacional.

\subsection{As fontes do direito da integração a partir de uma raiz internacionalista}

Há certo consenso na doutrina em relação ao rol de fontes do direito internacional, desglosado no art. 38 do Estatuto da Corte Internacional de Justiça, que, assim, prevê: tratados internacionais, costume internacional, princípios gerais de direito, decisões dos tribunais internacionais de justiça enquadradas como fonte jurisprudencial e a doutrina. Há ainda outras classificações que englobam, por exemplo, também as decisões de organizações internacionais, as decisões de tribunais de arbitragem e os atos unilaterais ${ }^{25}$.

Como tal, o Tratado que institui um processo de associação entre os Estados, na modalidade de cooperação

24 Vale a pena citar o pensamento de Isaac para quem "Llamamos orden jurídico al conjunto organizado y estructurado de normas jurídicas, que poseen sus propias fuentes, dotado de órganos y procedimientos aptos para emitirlas, interpretarlas, así como constatar y sancionar sus incumplimientos y violaciones." ISAAC, Guy. Manual de Derecho Comunitario general. $5^{a}$ edición. Madrid: Ed. Ariel, 2000, p. 155.

25 Vide como exemplo a análise feita por NASSER, Salem Hikmat. Fontes e normas do direito internacional: um estudo sobre a soft law. São Paulo: Atlas, 2006. ou na modalidade de integração, diferencia-se dos tratados internacionais de natureza clássica, constitutivo das organizações internacionais globais. Um tratado clássico pode ser definido, conforme preceitua a Convenção de Viena dos Direitos dos Tratados, como um "acordo internacional concluído entre os Estados na forma escrita e regida pelo direito internacional, que pode consistir em um único instrumento, tanto como dois ou mais instrumentos conexos, qualquer que seja sua denominação específica."

A definição clássica de tratados não inclui qualquer referência à forma de associação ou relações entre os estados, mas genericamente determina submissão às regras do direito internacional. Considerando-se a definição já referida, pode-se observar que esta não logra alcançar a produção normativa derivada da formação de processos de integração regional, ainda que os acordos baseados no direito internacional sejam considerados como fontes originárias do sistema normativo integrador.

Depois de citar as fontes do direito internacional, resta investigar, de forma sucinta, o sistema das fontes do direito da União Europeia. Em primeiro momento, cabe perguntar sobre os atos normativos relevantes da UE que especificam fontes. Qual seria a importância de se determinar o sistema das fontes do direito da União, se ele parece, à primeira vista, conformar-se pelos tratados constitutivos e outros acordos responsáveis pelo "alicerce" do sistema normativo comum? A criação de um sistema comunitário de fontes normativas é, particularmente, importante para determinar a natureza dos atos das instituições comunitárias e para compreender o alcance e os efeitos surgidos com base em uma ordem jurídica diferente da ordem internacional e das normas que compõem o direito nacional dos Estados-Membros. Molina del Pozo salienta a importância de se definir as fontes jurídicas da UE, como meio de determinar o âmbito de validade das regras. Para este autor,

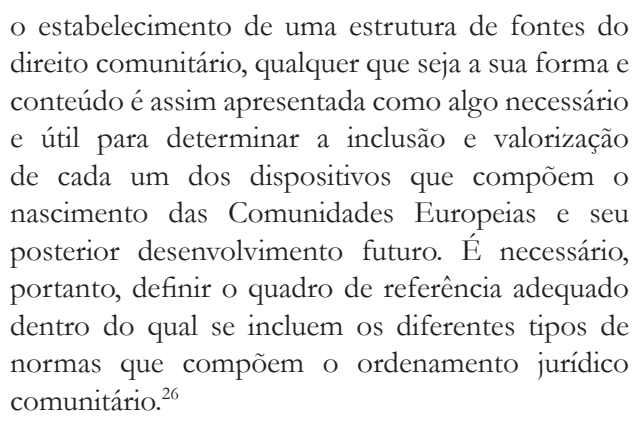

26 No original: El establecimiento de una estructuración de las fuentes del Derecho comunitario, sea cual sea su forma y contenido, se presenta, pues, como algo necesario y útil a la hora de determinar 
As principais fontes do direito da União são formadas com base no estabelecimento de tratados constitutivos (TCECA e TCEE), tratados de adesão - relacionados com as alterações derivadas da introdução de novos membros por ocasião de cada rodada de ampliação - e os tratados que foram feitos para a formação e desenvolvimento de uma união econômica, monetária e jurídica, aqueles que aportaram novos instrumentos jurídicos para a realização do mercado comum, bem como para o funcionamento das instituições (são os chamados Tratado da União Europeia, firmados em Maastricht, Amsterdam, Nice e Lisboa).

Como fonte de direito primário, os tratados estabelecem as principais ações das instituições, dos órgãos, dos Estados-Membros, atingindo, inclusive, as condutas que devem ser observadas pelos cidadãos. Como dito acima, para muitos, os Tratados poderiam ser considerados como verdadeira "Constituição", ao enquadrar as normas comunitárias em um sistema jurídico próprio distinto dos sistemas nacionais e internacional.

Fazendo uma breve análise da legislação da UE, podemos dizer que as normas originárias da UE, embora surgidas de uma fonte convencional (o tratado), resultam de atos jurídicos interestatais que envolvem sujeitos próprios de um sistema de coordenação avançado ${ }^{27}$, ou em certos casos até mesmo de subordinação, ao determinar a matriz de incidência das demais normas que compõem a ordem comunitária. Os tratados constitutivos e outros instrumentos criam obrigações para os Estados dentro de um quadro formal de direito internacional, mas que também têm efeitos que ultrapassam a conformação clássica internacionalista, já que criam um novo sistema legal - comunitário - com suas características próprias, do qual surgem regras fundamentais, com hierarquia superior à norma nacional e que fundam um conjunto de normas jurídicas a ele subordinado: o direito secundário, composto pelos regulamentos, diretivas e decisões emanados das instituições comunitárias e que

la inserción y valoración de cada uno de los actos dispositivos que configuran el nacimiento de las Comunidades Europeas y todo su posterior desarrollo. Es conveniente, por tanto, fijar el marco referencial apropiado dentro del cual habrían de incluirse las diferentes tipologías de normas que conforman el ordenamiento jurídico comunitario. MOLINA DEL POZO, Carlos F. Manual de Derecho de la Comunidad Europea. $4^{\text {a }}$ ed. Madrid: Dijusa, 2002, p. 457.

27 ARBUET-VIGNALI, Heber. Claves jurídicas de la Integración. En los sistemas del MERCOSUR y la Unión Europea. Santa Fe: Ed. Rubinzal-Culzoni, Santa Fe, 2004, p. 185. se regem por princípios singulares ${ }^{28}$, conforme será analisado posteriormente.

Em relação ao direito da integração no âmbito do Mercosul, as normas originárias compreendem, essencialmente, o Tratado de Assunção, o Protocolo de Brasilia, o Protocolo de Ouro Preto, conforme o art. 41 do Protocolo de Ouro Preto e nos termos do art. 19 do Protocolo de Brasíliaa ${ }^{29}$. Apesar de não estarem expressamente mencionados em ambos os artigos, tanto o Protocolo de Olivos como o Protocolo de Las Leñas, bem como o Protocolo de Santa Maria, devem ser considerados como fonte de direito originário ${ }^{30}$. Também os acordos firmados com outras organizações e/ou sistemas de integração e o Mercosul, bem como aquelas firmados com os estados associados, caso do Peru, Chile, Bolívia etc., podem ser considerados fontes originárias do direito mercosulista.

Esses instrumentos devem ser considerados como mandamentos de máxima observância, o que implica que todas as outras normas do MERCOSUL devem a eles se submeter, atuando como uma fonte primária para a aplicação e execução dos objetivos delineados pelos estados partícipes. Normas fundamentais ou constitutivas de objetivos pontuais do MERCOSUL são responsáveis por projetar um sistema de produção de normas e procedimentos de aplicação dos atos produzidos pelos órgãos comuns, embora o processo sub-regional do Cone Sul careça de instituições comunitárias com competências definidas para aplicar e garantir o devido cumprimento das normas por eles produzidas ${ }^{31}$.

O Tratado do Mercosul possui base claramente internacionalista ${ }^{32}$, mas os seus objetivos foram expressa-

28 MATA DIZ, Jamile B. MERCOSUR: orígen, fundamentos, normas y perspectivas. Curitiba: Juruá, 2007, p. 228.

29 DROMI, Laura San Martino. De la nueva historia del Derecho. A propósito del objeto, método y fuentes del Derecho del MERCOSUR. Buenos Aires: Ed. Ciudad Argentina, 1997, p. 108110.

30 Para Díaz Labrano os Protocolos de las Leñas e de Santa María são normas derivadas porque apesar de adotar a forma de protocolos internacionais "son de carácter instrumental para operativizar el proceso de integración o para armonizar jurídicamente la legislación de los Estados Parte." Mientras que los acuerdos de complementación económica son, para este autor, normas originarias. DÍAZ LABRANO, Roberto Ruiz. Integración y Derecho. Buenos Aires: Ed. Ciudad Argentina, 1998, pp. 521-522.

31 MATA DIZ, Jamile B. MERCOSUR: orígen, fundamentos, normas y perspectivas. Curitiba: Juruá, 2007, p. 245.

32 PEÑA, Felix. Reglas de juego, instituciones e integración económica: Reflexiones en una perspectiva del MERCOSUR. Fundación BankBoston, oct. 2002, disponível em http:// 
mente definidos com base na concepção de um processo de integração regional, divergindo, portanto, de uma natureza meramente cooperativa. As normas derivadas dos órgãos do Cone Sul também se caracterizam por uma abrangência menor do que aquela vinculada ao direito internacional. Ainda que atuem para além das fronteiras nacionais, devem ser plenamente respeitadas pelos Estados-Membros, porque foram criadas e aceitas espontaneamente. Os resultados dos acordos interestatais, tais como os firmados no âmbito do MERCOSUL, devem irradiar e propagar efeitos não só nos Estados mas também sobre as pessoas.

O problema de um sistema de fontes reside nas diferentes interpretações adotadas pelos Estados-membros do MERCOSUL, cujas Constituições nacionais têm distinções quanto à preponderância de ato externo formulado por um órgão supraestatal ${ }^{33}$. $\mathrm{O}$ resultado das assimetrias, sem dúvida, pode determinar o avanço ou retrocesso do processo de integração e prejudicar ou favorecer a formação de um sistema institucional supranacional.

A instituição de um sistema de fontes do MERCOSUL, caso seja considerado como um processo complexo de integração regional, diferenciado de um mero processo de cooperação econômica, é essencial para fixar o grau de aplicabilidade das regras comuns, estabelecendo uma "hierarquia" entre as normas de direito interno e as normas comunitárias, embora a regulação específica e própria do sistema integrador possa reforçar e acentuar a divisão de poderes entre as organizações regionais e os Estados-Membros que a formam. A distinção entre a ordem supranacional, proveniente de instituições comuns, e a ordem interna é essencial para localizar e corrigir o nível de efetividade e observância das regras produzidas por tais instituições ${ }^{34}$. Assim, a aplicação das regras comunitárias no âmbito dos Estados-Membros é inegavelmente mais consistente e impositiva, do ponto de vista da obrigação de cumprimento por parte dos estados, do que aquela resultante da maioria dos atos internacionais convencionais ${ }^{35}$.

www.fundacionbankboston.com.ar/inst/sec10/docs-felixpena/ articulos/2002-10-reglas-instituciones.doc, acesso em 12 set 2008.

33 MATA DIZ, Jamile B. MERCOSUR: orígen, fundamentos, normas y perspectivas. Curitiba: Juruá, 2007.

34 Para a distinção entre as fontes intra e extra-estatais recomenda-se a leitura de GALATERIA, Luigi; STIPO, Massimo. Manuale di Diritto Amministrativo. Roma: Ed. Torino, 1995, p. 36-40.

35 MATA DIZ, J. B. MERCOSUR: orígen, fundamentos, normas y perspectivas. Curitiba: Juruá, 2007.
A doutrina majoritária ${ }^{36}$ entende que o Mercosul é um processo amparado pelos princípios da integração, uma vez que está em uma zona intermediária entre a cooperação e a comunitarização, sendo considerado, portanto, como um processo de integração que pretende chegar a formar um mercado comum. A integração seria o instrumento adequado para regular o comportamento dos Estados-Membros e das pessoas - públicas e privadas - bem como dos atos ditados pelos órgãos do processo no âmbito do Mercosul. No entanto, esse direito, por sua singularidade e aspecto inovador, está consubstanciado pelos limites da ordem interna de cada particípe e como tal circunstância determina a necessidade de mandamentos imperativos para fazer cumprir a norma acordada nos órgãos integradores.

\subsection{A inter-relação direito internacional, direito da integração, direito comunitário e direito in- terno}

O direito da integração provém de relações específicas de cada estado, com os seus objetivos próprios e diferenciados daqueles aplicados pelo direito internacional público, embora, em certos momentos, possa utilizar-se de fontes jurídicas internacionais como método interpretativo e como forma de regulação ${ }^{37}$ (nesse caso, queremos dizer, principalmente, direitos humanos, direito comercial, resolução de conflitos etc.), de modo que suas funções possam ser salvaguardados pelas autoridades do Estado dos Estados-Membros em conjunto com os órgãos intergovernamentais (na ausência, por exemplo, de uma corte ou tribunal). ${ }^{38}$

Tanto no caso da União Europeia (em maior medi-

36 Vide por todos DÍAZ LABRANO, Roberto Ruiz. Diferencias Institucionales en los distintos esquemas de integración. In: Integración Eurolatinoamericana. MOLINA DEL POZO, Carlos F. (coord.). Buenos Aires: Ed. Ediciones Ciudad Argentina, 1996. 37 Essa regulação ocorre principalmente através da harmonização legislativa entendida como "a existência de esforços consistentes dos Estados-membros com vistas à adoção de normas coerentes e simétricas, não se podendo olvidar que em situações pontuais as exceções seriam bem toleradas." MORAES, Isaias Albertin de; MORAES, Flávia Albertin de; MATTOS, Beatriz R. Bessa. O Mercosul e a importância de uma legislação ambiental harmonizada. Revista de Direito Internacional, Brasília, v. 9, n. 3, 2012, p. 100.

38 GATTINONI DE MUJÍA, Maria C. El diálogo entre el juez de la jurisdicción nacional y el juez comunitario - Un análisis de la revisión prejudicial en Europa y en América Latina. Jornadas de Derecho Internacional. Organización de los Estados Americanos, Academia Diplomática del Perú. Lima, 17 al 20 de noviembre de 2003 (formato paper). 
da) como do MERCOSUL (em menor medida), a integração manifesta-se por regras de produção em diversas áreas, determinando aos Estados participantes no processo de integração uma obrigação de cumprimento que pode, contudo, resultar enfraquecida pela ausência de mecanismos institucionais comuns. No entanto, isso não resulta em falta de reconhecimento - especialmente no caso do Mercosul - de um direito específico e próprio, apenas torna-se ponto de destaque a falta de coercibilidade necessária para avançar na implementação de um mercado comum. Em igual sentido, assim manifesta Díaz Labrano ${ }^{39}$ :

além de qualquer discussão ou ceticismo sobre o direito que emana do MERCOSUL, a realidade se impôs e é fácil perceber com nítidos perfis a existência de um ordenamento jurídico de integração especial: direito da integração, que vem promovendo alterações substanciais na relacionamento dos Estados Partes e dos cidadãos no espaço integrado, ao mesmo tempo coloca o MERCOSUL como uma entidade jurídica que tem intensamente se relacionado com Estados e blocos semelhantes.

Pode parecer paradoxal a existência de um direito que não forneça os instrumentos jurídicos e os imperativos legais para conformar um substrato normativo que venha a determinar e limitar a atuação do estado que participa de um espaço multinacional integrado. A realidade nos leva a aceitar não só a existência desse direito, mas defender até mesmo sua aplicabilidade, mesmo que ainda não integralmente observado pelos Estados.

Se considerarmos o Mercosul como um processo de integração, não meramente de cooperação, devemos, também, compreender que este define-se por um sistema normativo, que não é internacional nem nacional - ainda que nasça ou se origine de um acordo internacional - mas que avança no sentido de estabelecer uma ordem jurídica própria. Vale ressaltar que o Mercosul não é produto de uma entidade estatal única, sendo, por outro lado, resultado da vontade política, econômica,

39 No original: Más allá de cualquier discusión o escepticismo en torno del derecho emanado del MERCOSUR, la realidad se ha impuesto y es fácil percibir con perfiles nítidos la existencia de un ordenamiento jurídico especial de integración: el derecho de la integración, que viene impulsando transformaciones sustanciales en el reracionamiento de los Estados Parte y de los ciudadanos en el espacio integrado, al mismo tiempo de ubicar al MERCOSUR en una entidad con personalidad jurídica que desarrolla una intensa actividad con Estados y bloques similares. DÍAZ LABRANO, Roberto Ruiz. Integración y Derecho. Buenos Aires: Ed. Ciudad Argentina, 1998, p. 524. social de um conjunto de estados ${ }^{40}$. Além disso, não se pode negar que a distinção entre direito da integração, direito internacional e direito interno envolve uma abordagem complexa e multifacetada, que merece, por sua vez, um tratamento teórico também diferenciado.

A formação de um direito da integração deve responder rapidamente às questões levantadas pelo desenvolvimento do processo de integração e deve ser capaz de regular a conduta dos envolvidos, determinar o nível de observância das normas, controlar a atuação dos órgãos comuns e, finalmente, determinar as sanções devidas em caso de descumprimento do acervo normativo. Mas como um sistema normativo será aplicado se não existem instituições que possam garantir o funcionamento pleno e eficaz de tal sistema? Será que o direito da integração consegue "fazer cumprir" as normas adotadas pelos partícipes sem um quadro institucional que venha a assegurar o devido funcionamento e aplicação das normas desse direito advindas?

Claro está que um ordenamento comunitário prima, incondicionalmente, sobre toda e qualquer norma estatal, incluídas as de natureza constitucional, em virtude de suas características especificamente originais. Os critérios de estrita juridicidade que informam o direito comunitário determinam que, contrariamente ao que ocorre no direito internacional ou no direito da integração, a mera manutenção em vigor de uma norma contrária àquele direito resulte em afronta ao princípio da primazia, resultando numa violação direta do direito comunitário ${ }^{41}$. O direito comunitário baseia-se, conforme será analisado posteriormente, em três princípios básicos e elementares: a primazia, a aplicabilidade imediata e o efeito direto ${ }^{42}$, determinados, em maior ou menor

40 SAVID-BAS, Luis I. Los actos obligatorios de los órganos del MERCOSUR, los sistemas constitucionales y la división republicana de poderes. In: Chile y el MERCOSUR en América Latina. IRIGOIN BARRENNE, Jeannete (coord.). Santiago: Ed. Jurídica de Chile, 1999, p. 221.

41 MONSANTO, Alberto. Dimensión jurídico-institucional del MERCOSUR. In: Estado, Mercado y Sociedad en el MERCOSUR, vol. I. LAREDO, Iris (org.). Rosario: Editorial Universidad Nacional de Rosario, 1993.

42 "Na União Europeia (...) vigora um direito específico e peculiar que é o Direito Comunitário, de caráter supranacional e dotado das seguintes características: aplicabilidade direta (vale dizer que a norma do bloco não necessita ser internalizada nos ordenamentos jurídicos dos Estados), primazia frente às normas nacionais (naqueles eventos em que, caso as normas nacionais conflitem com as normativas do bloco, sempre terão primazia as primeiras) e a uniformidade na interpretação e na aplicação das normativas." GOMES, Eduardo Biachi. Integração econômica no MERCOSUL: opiniões 
medida, nos tratados constitutivos.

O direito da integração, ao contrário, não obedece os pressupostos jurídicos do direito comunitário. Não se deve olvidar a existência de sistema de princípios cuja força imperativa radicaria nos elementos citados, senão que se determinam com base no binômio direitos internos/direito internacional público. ${ }^{43}$ Isso ocorre porque, em algumas circunstâncias, dependendo da etapa de integração em que os estados se encontram, há uma carência de mecanismos institucionais aptos a garantir a criação, execução e o controle tanto dos atos nacionais quanto intergovernamentais (adotados no âmbito dos órgãos), além de não possuir um sistema jurídico complexo como é o caso do direito comunitário; mas, nem por isso se pode considerá-lo como um mero apêndice do direito internacional público.

A doutrina internacionalista tradicional geralmente reconhece, apenas, dois resultados qualitativamente expressos pelos processos de integração: a cooperação e a comunitarização. No entanto, não se pode ignorar que há um estágio intermediário entre os dois processos, cuja manifestação se expressa pelo direito de integração. Caracterizá-lo como um elemento relacionado com o direito internacional (processo de cooperação) determinaria uma distorção da natureza específica das normas produzidas no âmbito de processos de integração subregionais, conforme as conclusões apresentadas pelo Informe final produzido no Seminário sobre "Las normas de Derecho Originario y Derivado del MERCOSUR", em seu item 13

\footnotetext{
Aceitar a possibilidade da existência de novas categorias de direito, além daquelas atualmente vigentes, o que resultaria na aceitação da existência de um direito regional, diferente do direito internacional público, direito comunitário e do direito interno. ${ }^{44}$
}

consultivas e a democratização no acesso ao tribunal permante de revisão. Revista de Direito Internacional, Brasília, v. 10, n 1, jan./ jul. 2013, p. 131.

43 CALIGIURI AMMENDIOLA, Eugenio R. FIGUEROA VEJAR, Alejandro A. Los principios de primacía y operatividad en el Derecho Comunitario como fundamento para la integración Latinoamericana. American Diplomacy, vol. 5, n. 01, North Carolina, invierno 2000.

44 No original: Aceptar la posibilidad de la existencia de nuevas categorías de derecho además de las actualmente vigentes, lo que redundaría en la aceptación de la existencia de un derecho regional, diferente del Derecho Internacional Público, del Derecho Comunitario y del Derecho interno. Seminario Las normas de Derecho Originario y Derivado del MERCOSUR - Su incorporación a los ordenamientos jurídicos de los Estados Partes. Secretaria del Merco-
Caso se adote um método jurídico científico, moldado pelas crescentes mudanças sociais, pode-se afirmar que, no caso do Mercosul, apesar das deficiências e problemas, existe um processo inclusivo que vai além das fronteiras da cooperação, abrangendo áreas de significativo valor social (por exemplo, as normas relativas a direitos sociais e outros de natureza fundamental que se consubstanciam em Declarações, Decisões etc.).

\section{A MATRIZ PRINCIPIOLÓGICA DO DIREITO DA IN- TEGRAÇÃO REGIONAL}

Os princípios do direito da integração nascem do direito internacional, mas, posteriormente, adquirem natureza própria, como é o caso da gradualidade, da flexibilidade e do equilíbrio, todos eles calcados, em maior ou menor medida, no princípio do tratamento diferenciado; bem como os princípios da primacía, da aplicabilidade imediata e do efeito direito no caso do direito europeu. A interpretação e aplicação dos referidos princípios ocorre em concordância com o objetivo especificado por cada processo de integração, considerando-se as assimetrias existentes no âmbito interno destes processos. Além disso, conforme ressalta Arbuet-Vignali ${ }^{45}$,

\begin{abstract}
ao aparecer um processo de integração mais profundo, que requer um novo sistema jurídico para ordenar-se, volta-se a atualizar a necessidade de princípios, mais do que como uma resposta doutrinária, como uma exigência da prática e para permitir desenvolver, ordenar e encaminhar corretamente a vontade política dos Estados no sentido de integrar-se, obrigando-se profundamente sem confundir-se num novo Estado que os abarque, nem perder sua independência (...) Os processos de integração profunda seriam muito difíceis de concretizar sem sólidos princípios que lhes assistissem
\end{abstract}

sur, CARI/Argentina, BID/INTAL, Fundación Konrad Adenauer, Uruguay, 26-27 setembro 2002, p. 3 (formato paper).

45 No original: $\mathrm{Al}$ aparecer un proceso de integración más profundo, que requiere un nuevo sistema jurídico para ordenarse, se vuelve a actualizar la necesidad de principios, más que como una respuesta doctrinal, como una exigencia de la práctica y para permitir desarrollar, ordenar y encauzar correctamente la voluntad política de los Estados en el sentido de integrarse, obligándose profundamente sin confundirse en un nuevo estado que los abarque, ni perder su independencia (...) Los procesos de integración profunda serían muy difícil de concretar sin principios sólidos que les asistieran. ARBUET-VIGNALI, Heber. Claves jurídicas de la Integración - En los sistemas del MERCOSUR y la Unión Europea. Ed. Rubinzal-Culzoni, Santa Fe, 2004, p. 338. 
Em muitas partes do Tratado de Assunção (TA), pode-se encontrar, implícita o explicitamente, os princípios que servem como condutores do processo de integração. De maneira geral, esses princípios referem-se às condições necessárias para o devido desenvolvimento do mercado comum, caso do princípio da não discriminação (art. 8, d) que deve ser aplicado no Programa de Liberação Comercial para o Paraguai e o Uruguai (art. 6); na transparência aplicada na coordenação das políticas nacionais de modo a garantir condições equitativas de comércio con terceiros países y assegurar que seja aplicada condições iguais no tratamento comercial extrazona (art. 4); princípio da reciprocidade de direitos e deveres entre os Estados (art. 2); entre outros ${ }^{46}$.

A importância dos princípios de gradualidade, flexibilidade e equilíbrio foi analisada e ressaltada por distintos autores, considerando-se, também, que o princípio da reciprocidade encontraria-se, ainda que implicitamente, incluído no rol de princípios previsto no TA. Ainda conforme Gross Spiel" ${ }^{47}$, "los principios de gradualidad, flexibilidad y equilibrio informan, dan sentido y contenido a todo el proceso de creación y conformación del MERCOSUR, y deben ser aplicados en cada etapa y negociación relativa a los Derechos y deberes de las partes."

O princípio da gradualidade deve ser entendido como a adoção de maneira gradual e progressiva dos postulados que regem um mercado comum. Previsto anteriormente pelo Tratado de Montevideu de 1960 e também pelo de 1980. Esse princípio define as etapas necessárias para o desenvolvimento por etapas do processo de integração. Conforme especifica Ventura ${ }^{48}$, esse princípio pode ser interpretado tanto num plano vertical, em que o início de uma nova etapa estaria condicionada ao termo da etapa precedente, quanto num plano horizontal, vinculado à coordenação de distintos instrumentos que subjazem às etapas consecutivas.

O princípio da flexibilidade, como bem expressa o próprio nome, determina uma margem de manobra para que os Estados possam adotar e cumprir as obriga-

46 ESTRELA FARIA, José A. O Mercosul: princípios, finalidades e alcance do Tratado de Assunção. Ministério das Relações Exteriores, Brasília, 1993, p. 3-8.

47 GROSS ESPIELL, Hector. Tratado de Asunción: una aproximación a su problemática jurídica. Rev. de la Facultad de Derecho de Montevideo, n. 01, jul./dic. 1991, p. 21.

48 VENTURA, Deisy. As assimetrias entre o Mercosul e a Uniao Europeia. Sao Paulo: Ed. Manole, 2002, p. 44. ções relacionadas com o sistema jurídico fixado no TA, de uma maneira elástica e menos rígida. Como princípio previsto no Tratado de 1992, a flexibilidade se manifesta mais na forma que no conteúdo propriamente dito dos atos jurídicos mercosurlistas, ainda que não se pode desconhecer a excessiva flexibilidade adotada pelos Estados na formulação de um sistema institucional que resulte em maior segurança jurídica.

O princípio do equilíbrio visa garantir condições de igualdade entre todos os Estados partes. Claro está que o objetivo principal consiste em evitar os conflitos derivados que surgem da aplicação das diferentes legislações nacionais e por práticas comerciais de natureza claramente protecionista e distorsiva do mercado comum. Contudo, o equilíbrio não deve buscar, necessariamente, uma completa uniformidade entre a ordem interna nacional e a ordem comum, mas deve servir para corrigir as "assimetrias" surgidas no decorrer do processo de integração ${ }^{49}$. O tratamento desigual entre os Estados-partes não supõe, per si, um tratamento discriminatório, já que, em algumas ocasiões, um determinado país necessita de um tempo maior e/ou circunstâncias mais maleáveis para adequar-se à normativa comum quando comparado com os demais estados. O limite da igualdade deve ser formulado pelos próprios signatários do Tratado e pode ser garantido pela adoção de normas de caráter obrigatório que estabeleçam prazos ou condições de cumprimento especial por parte do membro favorecido ${ }^{50}$.

Finalmente, o princípio da reciprocidade possibilita adotar mecanismos de controle de aplicação de normas e instrumentos pelos Estados partes, assegurando que a incorporação da normativa comum seja realizada de maneira equivalente e recíproca entre todos os signatários. Além disso, torna-se elemento intrínseco à própria existência do mercado comum ao permitir o desenvolvimento do reconhecimento mútuo. Esse princípio deve ser interpretado com os demais princípios, especialmente o do equilíbrio, já que se inclui no quadro geral de vantagens e concessões mútuas dadas aos países

49 MATA DIZ, Jamile B. MERCOSUR: orígen, fundamentos, normas y perspectivas. Curitiba: Juruá, 2007, p. 156.

50 Lorezentti faz distinção entre os princípios estruturais: o respeito à ordem democrática; respeito pelos direitos humanos; desenvolvimento econômico com justiça social; proteção ambiental e transparência do mercado, e os princípios processuais: a gradualidade; reciprocidade e solidariedade. $\mathrm{O}$ autor refere-se ainda aos princípios relativos à liberdade de circulação de pessoas. LORENZETTI, Ricardo. Sistema jurídico del MERCOSUR. Rev. Jurisprudencia Argentina, Tomo E, Buenos Aires: Ed. La Ley, 1998, p. 1258-1275. 
participantes do processo de integração ${ }^{51}$.

Em relação aos princípios da União Europeia, pode-se citar, sem ânimo de esgotar o tema, aqueles que conformam a supranacionalidade normativa sendo atributos de tal modalidade de integração:

1) A primacía implica que, em caso de conflito, as normas comunitárias devem aplicar-se com prevalência sobre as nacionais, qualquer que seja a hierarquia ou posição das normas e com prescindência de aprovação interna posterior. Em outros termos, significa que, em caso de contradição entre uma norma comunitária e uma norma de direito interno, deve prevalecer a norma comunitária ${ }^{52}$. Essa supremacía incondicional e absoluta do direito comunitário fundamenta-se em sua natureza de ordenamento jurídico autônomo e é consequência direta da aplicabilidade imediata e do efeito direto, já que esses princípios determinam que as normas comunitárias sejam aplicadas de maneira geral, uniforme e incondicionada em todos os estados participantes, revogando, em caso de controvérsia, as normas de direito interno opostas ou contrárias às de direito comunitário. ${ }^{53}$

2) Efeito direito: o efeito direto ou aplicabilidade direta está intimamente relacionado com a aplicabilidade imediata e alude à capacidade do direito comunitário de gerar direitos e obrigações para os estados, instituições e cidadão. Seu efeito refere-se à possibilidade de que toda e qualquer pessoa possa demandar ao juiz nacional a aplicação do direito originário e derivado e a obrigação dos juízes de aplicar as normas comunitárias, qualquer que seja a legislação nacional do país, tanto nas relações entre particulares, como naquelas feitas entre estes e os Estados, bem como nas de natureza interestatal ${ }^{54}$. A doutrina $a^{55}$ e a jurisprudência fazem distinção entre

51 Sobre a incompatibilidade entre a reciprocidade e o tratamento diferenciado deve-se citar a TABARÉ, Vasquez y BIZZOZERO, Lincoln. La construcción del MERCOSUR: diagnóstico y evaluación de lo acordado. BID/INTAL, Buenos Aires, 1994, p. 12.

52 Neste sentido conforme ressalta Vidigal ao comentar a sentença Costa Enel emitida pelo então Tribunal de Justiça da Comunidade Europeia, "Consagra-se, pois, no Direito Comunitário, o chamado Princípio da Supremacia e do Efeito Direto, o que eleva os Tratados que instituem a Comunidade à condição de verdadeira Carta Constitucional". VIDIGAL, Erick. O regime jurídico das integrações político-econômicas regionais. Revista de Direito Internacional, Brasília, v. 8, n. 2, jul./dez. 2011, p. 103.

53 MATA DIZ, Jamile B. El sistema de incorporación de normas en el MERCOSUR: la supranacionalidad plena y la vigencia simultánea. Rev. Ius et Praxis, vol. 10, n. 02, Chile: Universidad de Talca, ago./dic. 2005, p.227 - 260.

54 MOLINA DEL POZO, Carlos F. Manual de Derecho de la Comunidad Europea. $4^{\text {a }}$ ed. Madrid: Dijusa, 2002, p. 822.

55 PALACIO GONZÁLEZ, Jose. El efecto directo: ¿Un con- o efeito direto horizontal, compreendido como a possibilidade de que o particular possa invocar as normas comunitárias tanto frente aos Estados como em relação a outro particular; e o efeito direto vertical: representa o fundamento inicial da construção do princípio, ao pregar a possibilidade de invocar as normas ante o estado que infringe ou não internaliza a norma comunitária.

3) Aplicabilidade imediata: a aplicabilidade imediata de uma norma comunitária implica que esta adquire automaticamente status de direito positivo na ordem interna dos Estados-membros, sem que haja procedimento nacional de incorporação ou internalização de norma ao ordenamento jurídico interno. Os poderes e órgãos dos Estados estão obrigados a aplicar as normas comunitárias, não podendo invocar razões de ordem constitucional ou supralegal para não fazê-lo. Na UE, o direito comunitário, em seu conjunto, goza de aplicabilidade imediata e se integra aos ordenamentos jurídicos nacionais pelo simples fato de ser a norma publicada no Diário Oficial da União Europeia.

\section{O OBJETO DO DIREITO DA INTEGRAÇÃO E A ES- PECIFICIDADE DAS RELAÇÕES INTERESTATAIS}

Os destinatários de um processo de integração serão sempre os cidadãos, a sociedade em geral, mas seus sujeitos são os entes estatais, reunidos numa espécie de associação tendente a criar vínculos mais profundos que aqueles estabelecidos num tratado internacional. Nesse sentido, os sujeitos da integração são os Estados - na mesma acepção do direito internacional público - mas a integração modifica substancialmente os elementos clássicos utilizados para a definição destes, ao possibilitar a livre circulação de pessoas, bens, serviços e capital.

Num sistema de cooperação interestatal clássico, calcado nos postulados do direito internacional, as transformações não afetam, na essencialidade, a todos os elementos do Estado, já que não acarreta, em geral, uma mutação no território e na população, ainda que possa modificar, em maior ou menor grau, o exercício do poder soberano por esse Estado, na medida em que, ao integrar-se a outro sujeito de direito internacional (seja Estado ou organização internacional), deverá submeter-

cepto en crisis? Revista Comunidad Europea, año XXVIII, n. 8-9. Madrid: Ed. Aranzadi, 2001, p. 34-44. 
-se aos objetivos que compõem o acordo de associação ou adesão. Mas, mesmo nesse caso, o Estado continua com a integralidade do poder soberano, pois será o encarregado de decidir ou não pela respectiva participação na integração.

Num sistema de comunitarização, fundado nas premissas do direito da integração e ainda mais no direito comunitário, as transformações afetam, em maior medida, os elementos do Estado, uma vez que os resultados pretendidos supõem a criação de um arcabouço normativo destinado ao cumprimento dos objetivos de uma integração mais profunda. Assim, esse sistema pode estipular, por exemplo, modificações estruturais no território por meio da abertura das fronteiras com a consequente livre circulação; na população, ao promover um fluxo indefinido de "nacionais" e "estrangeiros", e garantir igualdade de tratamento para todos os habitantes dos Estados partícipes da integração, inclusive chegando a uma concepção elástica de "nacional" e até mesmo "cidadão"; e finalmente, uma alteração significativa na acepção clássica de soberania, especificamente no exercício das competências e poderes estatais, ao criar um sistema de decisão amparado em instituições e normas de natureza supranacionais, que deverão exercer as funções e tarefas que foram delegadas por estes Estados. É valido recordar que, obviamente, o Estado continua no exercício da soberania que lhe é inerente, mas deverá "compartilhá-la" com os demais Estados integrantes do processo associativo. Ainda, o Estado também poderá decidir pela participação ou não nesse tipo de integração e, por isso, discordamos dos autores que afirmam haver uma perda de soberania ${ }^{56}$.

Assim, o chamado "Ente" supranacional representa, em verdade, a junção da vontade de distintos Estados em compartilhar mecanismos e decisões de índole política e jurídica destinadas a fortalecer o papel e a atuação dos partícipes nas relações exteriores em geral, além de estabelecer direitos e garantias que venham a aperfeiçoar o sistema normativo protetivo dos direitos fundamentais destes mesmos Estados.

\subsection{A integração e o elemento território: as fronteiras de um espaço integrado}

56 MATA DIZ, Jamile B.; MARTINS, Thiago Penido. Por uma reinterpretação dos elementos do Estado a partir da criação e consolidação dos processos de integração regional. In: Direito Internacional. RAIZER, Valeska; Del'Olmo, Florisbal. XXIII Congresso do CONPEDI. Aracaju, junho 2015 (no prelo).
A permeabilidade das fronteiras possibilita que a integração possa atingir o objetivo estrutural e funcional de facilitar que os fatores produtivos, vinculados ao mercado, possam lograr maior liberalidade na circulação e consequente comercialização dos bens e produtos. Sob o prisma da circulação de pessoas, os obstáculos devem ser removidos de forma a promover e garantir a igualdade de direitos e o tratamento não discriminatório, tal e como aplicado na União Europeia.

No caso específico dos processos de integração, torna-se importante analisar, também, a questão da livre circulação sob a perspectiva da "derrubada" dos limites territoriais, ao expurgar a necessidade de controles mais rigorosos sobre a mobilidade transfronteiriça, em quaisquer de seus aspectos. Agora, deve-se ressaltar desde já que não há eliminação propriamente dita das fronteiras, mas a adoção de critérios flexíveis de mobilidade que permitam maior circulação dos fatores produtivos e pessoais. Conforme expressa Papadodima, "as mudanças associadas com as novas funções de fronteiras internacionais supõem que elas são agora mais permeáveis aos movimentos e fluxos transfronteiriços, apesar das fronteiras internacionais permanecerem bem demarcadas." ${ }^{57}$

\subsection{A formação de um substrato social baseado numa cidadania comum}

A criação de uma cidadania europeia traz importantes reflexos para as relações existentes entre os conceitos de povo, território e soberania. Segundo o preceito contido no artigo 20 do Tratado de Funcionamento da União Europeia (TFUE), toda pessoa considerada como nacional de qualquer dos Estados-Membros adquirirá, sem prejuízo de sua nacionalidade, a cidadania europeia, razão pela qual se tornam titulares de direitos e deveres perante a referida comunidade de Estados, tais como o direito de livre circulação e residência em qualquer dos territórios dos Estados-Membros, o direito de votar e ser votado nas eleições do Parlamento Europeu, bem como nas eleições do Estado-Membro em que estiver residindo, de buscar proteção e amparo em

57 No original: "Los cambios asociados a las nuevas funciones de las fronteras internacionales, hacen asumir que son ahora más permeables a los movimientos y flujos transfronterizos, aunque los límites internacionales continúan siendo bien demarcados." PAPADODIMA, Zampeta. Las fronteras regionales: la materia de migraciones en la Geopolítica contemporánea. Cuadernos geográficos de la Universidad de Granada, n 48. Granada: UGR, 2011, p. 193. 
qualquer Estado-Membro, mesmo que inexista órgão representativo do Estado de sua nacionalidade, direito de peticionar aos órgãos públicos, dentre outros ${ }^{58}$.

Agora bem, uma questão relevante vinculada à cidadania e a livre circulação de pessoas se refere ao tratamento não discriminatório que deve imperar em todo o território europeu. O Tratado da União Europeia obriga os países-membros da UE a lutar ativamente contra a discriminação, não somente contra a discriminação por nacionalidade, senão também por gênero, raça, origem étnica, religião ou crença religiosa, idade, incapacidade ou inclinação sexual. A Carta dos Direitos Fundamentais da União Europeia (CDF-2007) proíbe ademais a discriminação por características genéticas, cor de pele, idioma, ou ideias políticas ou de outro tipo, bem como pelo "vínculo" a uma minoria nacional. Também a Carta sublinha a igualdade ante a lei e a proibição da discriminação.

\subsection{A irradiação dos efeitos da integração sobre o poder soberano dos Estados}

O elemento mais contravertido no debate sobre os processos de integração está relacionado com a questão de transferência de competências ou cessão da soberania que, em tese, pode ser desenvolvida por cada Estado. Ao estabelecer as mudanças na estrutura interna dos Estados membros de um processo de integração regional, principalmente político, institui-se um novo modelo de formação estatal que, de certa maneira, influi no conceito clássico de soberania. Mas, a integração regional não é definitivamente incompatível com a soberania nacional. A potestade de um país não será menos absoluta, porque a força do poder soberano vincula-se à participação na própria integração regional. As relações do direito comunitário, por exemplo, não negam nem excluem a soberania. Ao contrário, conformam um marco ampliado, que estende ou prolonga o poder soberano de um Estado, já que agora há uma "compatibilidade" com o poder soberano de outros Estados membros.

Assim, pode-se observar que a integração aumenta, qualitativamente, a soberania dos países integrantes

58 MATA DIZ, Jamile B.; LEMOS Jr., Eloy. O direito fundamental à livre circulação de pessoas: as transformações nos elementos do Estado advindas dos processos de integração regionais. In: Sistema Jurídico e Direitos fundamentais individuais e Coletivos. MENEZES, Wagner; DEL'OLMO, Florisbal (coord.). Florianópolis: CONPEDI, 2012, p. 888-898. do processo e que a mesma não pode subsistir como conceito que imponha um obstáculo à liberdade de associação entre os Estados. É mister que se proceda à revisão do termo, procurando desmaterializar a afirmação assumida pelos defensores do Estado clássico de que a soberania é a razão primeira para a existência de uma Nação. É diferente a relação internacional entre Estados no marco do regionalismo puro ${ }^{59}$, pois neste a vinculação é de independência e autonomia, mais do que de soberania, porque o direito internacional se coordena direta e automaticamente ao direito interno de cada país.

No caso de processos de integração, a mudança nos conceitos de soberania aplicada em cada um dos Estados membros dependerá do grau de integração atingido, com o qual se pode reconhecer um "partilhar de soberania" mais ou menos aprofundado, segundo o sistema de integração que se deseja atingir com a associação interestatal. A discussão em torno do compartilhamento de competências se centra, principalmente, na questão de determinar se os Estados, enquanto integrados num espaço institucional unificado, determinam a constituição de elementos dissociativos da soberania nacional, perdendo parte das funções estatais tradicionais.

Devemos enfatizar que a concepção da soberania como um valor jurídico-político materializado pela independência e autonomia dos Estados, originou-se a partir dos supostos do chamado Estado-nação, durante os séculos XVIII e XIX, mas que conseguiu uma grande expansão modificativa a partir do século XIX e XX. A questão também demanda maiores reflexões sobre se o compartilhamento se refere ao conteúdo formal da soberania e das conseguintes competências ou funções estatais, ou se se refere ao exercício das competências

59 Deblock y Brunelle fazem distinção entre regionalismo e regionalização ao afirmar que "Le régionalisme peut être considéré, dans le sens étroit du terme, comme une option de politique comérciale, à côté du multilatéralisme et du bilatéralisme, et ensuite, comme un moyen de favoriser la coopération économique et une plus grande intégration institutionelle entre les pays concernés, dans une région donnée, et en fin comme une forme particulière d'alliance en vue de promouvoir des intérêts communs et certains intérêts stratégiques particuliers sur la scène économique internationale. La régionalisation renvoie à la concentration et à l'intensification des échanges, commerciaux ou financiers, de même qu'à l'élargissement et à l'approfondissement des réseaux financiers, de production, de communication et de mise en marché des produits dans une région donnée." DEBLOCK, Christian; BRUNELLE, Dorval. Lé régionalisme économique international: de la prèmiere à la deuxième génération. Tous pour un ou chacun pour soi. FORTMANN, Maurice et all. (org.). Québec: Institut québécois des hautes études internationales, 1996, pp. 271-316. 
dadas às instituições, fazendo com estas continuem pertencendo ao Estado, podendo ser executadas pelas instituições comunitárias ${ }^{60}$.

A partilha de competências entre os Estados e as instituições supranacionais se dá, basicamente, pela própria vontade daqueles ao fixar as matérias que serão atribuídas às esferas supranacionais. $\mathrm{O}$ debate se refere ao questionamento da própria divisão ou compartilhamento entre os poderes estatais e supranacionais, já que se fala de transferência das competências estatais ou transferência de seu exercício e que, apesar de ser uma discussão vigente, não desperta maiores dúvidas quando os países-membros de uma Comunidade estabelecem normas a partir de uma raiz institucional comunitária: o poder legislativo comum. Não obstante, cabe indagar sobre a formação de instituições e técnicas de criação de um direito supraestatal, com base em pressupostos conceituais da supranacionalidade e de seus respectivos atributos.

\section{Considerações finais}

O principal aspecto que restou evidenciado, com base nas experiências teóricas e práticas vinculadas ao tema da integração regional, foi a necessidade de estabelecer os pressupostos para a construção de uma teoria própria e autônoma que pudesse explicar a consequente evolução e o desenvolvimento, mesmo que fragmentado, deste tipo de associação interestatal. No intuito, conforme fixado na introdução deste artigo, de compatibilizar os reais mecanismos usados pelos Estados quando decidem criar um espaço integrado, diferenciado das tradicionais e clássicas fórmulas baseadas no direito internacional.

Nesse sentido, vale ressaltar que o debate sobre a autonomia do direito da integração, ao compará-lo com o direito da União Europeia, pode ser, ainda, estabelecido com base na perspectiva de ser este direito da integração evoluído, aperfeiçoado, presente na União Europeia, enfatizando-se ainda ser a questão intergovernamentalidade versus supranacionalidade a nota distintiva entre ambas as espécies de Direito. Com base nessa constatação, pode-se afirmar

60 MATA DIZ, Jamile B.; MARTINS, Thiago Penido. Por uma reinterpretação dos elementos do Estado a partir da criação e consolidação dos processos de integração regional. In: Direito Internacional. RAIZER, Valeska; Del'Olmo, Florisbal. XXIII Congresso do CONPEDI. Aracaju, junho 2015 (no prelo). que a autonomia do direito da integração, sob a perspectiva teórica, pode embasar-se no já tradicional esquema de etapas econômicas e naquele apresentado pela teoria das relações internacionais, mas deve ir além, ao consubstanciar os pressupostos jurídicos que venham a compreender e categorizar tal ramo do Direito.

Em primeira aproximação, repise-se, teórica, pode-se afirmar ter o direito da integração método, princípios, objeto e fontes próprios, condizentes, então, com sua autonomia em relação ao direito internacional e até mesmo ao direito da União. Ao caracterizar os processos de integração, numa configuração teórica jurídica, quer estejam situados em zonas mais ou menos desenvolvidas de integração (ou seja, podem classificar-se desde uma união aduaneira até uma união política), entre a comunitarização e a internacionalização das normas, encontrando-se, portanto, sob a égide do direito da integração, entendido este como um plexo de normas descritivas de uma conduta para a comunitarização, mas que também não se enquadram no direito internacional. Prima-se pelo reconhecimento de um sistema próprio, ainda que compartilhe mecanismos e fontes do direito internacional, mas que permite aos Estados associados integrar-se num acordo com disposições comuns, sem que tenha especificamente adotado a supranacionalidade num sentido amplo. As diferenças estruturais entre as instituições supranacionais, as organizações de integração e as relações de cooperação (internacional) resultam na diversidade da natureza jurídica, das funções, competências e alcance das atribuições de cada uma delas.

Finalmente, nesse breve escorço teórico, delineamos alguns dos pressupostos que devem ser levados em consideração quando defende-se uma autonomia do direito da integração que seja capaz, ainda que de forma incipiente, de explicar e analisar devidamente o fenômeno da integração interestatal.

\section{Agradecimento}

A coautora agradece ao Programa Erasmus+ Jean Monnet Chair activities 2015 - EAC/A04/2014 pelo financiamento dado para a realização da presente pesquisa no marco do projeto 565401-EPP-1-2015-1-BREPPJMO-CHAIR. O coautor agradece ao CNPq, que financiou a realização da presente pesquisa no Programa de Pós-Graduação em Direito da UFRGS no marco de uma Bolsa de Produtividade em Pesquisa. 


\section{REFERÊNCIAS}

ARBUET-VIGNALI, Heber. Claves jurídicas de la Integración en los sistemas del MERCOSUR y la Unión Europea. Santa Fe: Ed. Rubinzal-Culzoni, Santa Fe, 2004.

BETTTI, Emilio. Interpretação da Lei e dos atos jurídicos: teoria geral e dogmática. Trad.: Karina Janinni. $2^{\mathrm{a}}$ ed. - São Paulo: Martins Fontes, 2007.

CALIGIURI AMMENDIOLA, Eugenio R. FIGUEROA VEJAR, Alejandro A. Los principios de primacía y operatividad en el Derecho Comunitario como fundamento para la integración Latinoamericana. American Diplomacy, vol. 5, n. 01, North Carolina, invierno 2000.

CANARIS, Claus-Wilhelm. Pensamento sistemático e conceito de sistema na Ciência do Direito. $3^{\mathrm{a}} \mathrm{ed}$. Lisboa: Fundação Calouste Gulbenkian, 2002.

CRYER, Robert et all. Research methodologies in EU and International Law. Oxford and Portland: Hart Publishing, 2011.

DEBLOCK, Christian; BRUNELLE, Dorval. Lé régionalisme économique international: de la prèmiere à la deuxième génération. In : Tous pour un ou chacun pour soi. FORTMANN, Maurice et all (org.). Québec: Institut québécois des hautes études internationales, 1996, pp. 271-316.

DÍAZ LABRANO, Roberto Ruiz. Diferencias Institucionales en los distintos esquemas de integración. In: Integración Eurolatinoamericana. MOLINA DEL POZO, Carlos F. (coord.). Buenos Aires: Ed. Ediciones Ciudad Argentina, 1996.

DÍAZ LABRANO, Roberto Ruiz. Integración y Derecho. Buenos Aires: Ed. Ciudad Argentina, 1998.

DROMI, Laura San Martino. De la nueva historia del Derecho: a propósito del objeto, método y fuentes del Derecho del MERCOSUR. Buenos Aires: Ed. Ciudad Argentina, 1997.

ESTRELA FARIA, José A. O Mercosul: principios, finalidades e alcance do Tratado de Assunção. Ministerio das Relações Exteriores, Brasília, 1993.

FERRAZ JÚNIOR, Tércio Sampaio. Introdução ao Estudo do Direito: técnica, decisão, dominação. $6^{a}$ ed. - São Paulo: Atlas, 2008.
GALATERIA, Luigi; STIPO, Massimo. Manuale di Diritto Amministrativo. Roma: Ed. Torino, 1995.

GATTINONI DE MUJÍA, Maria C. El diálogo entre el juez de la jurisdicción nacional y el juez comunitario - Un análisis de la revisión prejudicial en Europa y en América Latina. Jornadas de Derecho Internacional. Organización de los Estados Americanos, Academia Diplomática del Perú. Lima, 17 al 20 de noviembre de 2003 (formato paper).

GOMES, Eduardo Biachi. Integração econômica no MERCOSUL: opiniões consultivas e a democratização no acesso ao tribunal permante de revisão. Revista de Direito Internacional, Brasília, v. 10, n 1, jan./jul. 2013.

GROSS ESPIELL, Hector. Tratado de Asunción: una aproximación a su problemática jurídica. Revista de la Facultad de Derecho de Montevideo, n. 01, jul./dic. 1991.

ISAAC, Guy. Manual de Derecho Comunitario general. $5^{a}$ edición. Madrid: Ed. Ariel, 2000.

JAEGER JUNIOR, Augusto. Metodologia jurídica europeia e mercosulista: considerações fundamentais. Revista da Secretaria do Tribunal Permanente de Revisão do Mercosul. Assunção: Secretaria do Tribunal Permanente de Revisão do Mercosul, a. 2, n. 3, mar. 2014. p. 117-157. Disponível em: http://www.revistastpr.com/index.php/rstpr/article/view/87/66, acesso em 13 mar 2015.

LAKATOS, Eva Maria; MARCONI, Mariana de Andrade. Fundamentos de metodologia científica: Técnicas de pesquisa. 3 ed. São Paulo: Atlas, 2003.

LOPEZ, Enrique Guillen. Metodología del Derecho Constitucional Europeo: Un derecho Constitucional para la integración política de Europa. Del pluralismo ideológico. Revista de Derecho Constitucional Europeo, n. 12, UGR, 2009.

LORENZETTI, Ricardo. Sistema jurídico del MERCOSUR. Revista Jurisprudencia Argentina, Tomo E, Buenos Aires: Ed. La Ley, 1998.

MATA DIZ, Jamile B. El sistema de incorporación de normas en el MERCOSUR: la supranacionalidad plena y la vigencia simultánea. Rev. Ius et Praxis, vol. 10, n. 02, Chile: Universidad de Talca, ago./dic. 2005.

MATA DIZ, Jamile B. MERCOSUR: orígen, fundamentos, normas y perspectivas. Curitiba: Juruá, 2007. 
MATA DIZ, Jamile B.; LEMOS Jr., Eloy. O direito fundamental à livre circulação de pessoas: as transformações nos elementos do Estado advindas dos processos de integração regionais. In: Sistema Jurídico e Direitos fundamentais individuais e Coletivos. MENEZES, Wagner; DEL'OLMO, Florisbal (coord.). Florianópolis: CONPEDI, 2012, p. 888-898.

MATA DIZ, Jamile B.; MARTINS, Thiago Penido. Por uma reinterpretação dos elementos do Estado a partir da criação e consolidação dos processos de integração regional. In: Direito Internacional. RAIZER, Valeska; Del'Olmo, Florisbal. XXIII Congresso do CONPEDI. Aracaju, junho 2015 (no prelo).

MAXIMILIANO, Carlos. Hermenêutica e aplicação do Direito. 19a ed. - Rio de Janeiro: Forense, 2002.

MOLINA DEL POZO, Carlos F. Manual de Derecho de la Comunidad Europea. $4^{\mathrm{a}}$ ed. Madrid: Dijusa, 2002.

MONSANTO, Alberto. Dimensión jurídico-institucional del MERCOSUR. In: Estado, Mercado y Sociedad en el MERCOSUR. LAREDO, Iris (org.). Rosario: Editorial Universidad Nacional de Rosario, 1993.

MORAES, Isaias Albertin de; MORAES, Flávia Albertin de; MATTOS, Beatriz R. Bessa. O Mercosul e a importância de uma legislação ambiental harmonizada. Revista de Direito Internacional, Brasília, v. 9, n. 3, 2012.

NASSER, Salem Hikmat. Fontes e normas do direito internacional: um estudo sobre a soft law. São Paulo: Atlas, 2006.

PALACIO GONZÁLEZ, Jose. El efecto directo: ¿Un concepto en crisis? Revista Comunidad Europea, año XXVIII, n. 8-9. Madrid: Ed. Aranzadi, 2001.

PALLARES, Beatriz y AGUZIN, Luiz. El régimen de incorporación de los tratados en el derecho interno. Congreso Internacional de Cultura y Sistemas jurídicos comparados. Instituto de Investigaciones Jurídicas. UNAM, México, 2004, p. 23, disponible em http://www.juridicas.unam.mx/inst/evacad/even- tos/2004/0902/mesa3/76s.pdf, acesso en 15 dec 2004

PAPADODIMA, Zampeta. Las fronteras regionales: la materia de migraciones en la Geopolítica contemporánea. Cuadernos geográficos de la Universidad de Granada, n 48. Granada: UGR, 2011, p. 193.

PEÑA, Felix. Reglas de juego, instituciones e integración económica: Reflexiones en una perspectiva del MERCOSUR. Fundación BankBoston, oct. 2002, disponível em http://www.fundacionbankboston.com. ar/inst/sec10/docs-felixpena/articulos/2002-10-reglas-instituciones.doc, acesso em 12 set 2008.

PEREZ OTERMÍN, Jorge. E1 Mercado Común del Sur - desde Asunción a Ouro Preto: aspectos jurídico-institucionales. Montevideo: Fundación de Cultura Universitaria, 1995.

POPPER, Karl S. A lógica da pesquisa científica. 2. ed. São Paulo: Cultrix, 1975.

RANGEL, Vicente Marotta. Direito e Relações internacionais. 2a. Ed. São Paulo: Editora RT. 1981.

SAVID-BAS, Luis I. Los actos obligatorios de los órganos del MERCOSUR, los sistemas constitucionales y la división republicana de poderes. In: Chile y el MERCOSUR en América Latina. IRIGOIN BARRENNE, Jeannete (coord.). Santiago: Ed. Jurídica de Chile, 1999.

Seminario Las normas de Derecho Originario y Derivado del MERCOSUR - Su incorporación a los ordenamientos jurídicos de los Estados Partes. Secretaria del Mercosur, CARI/Argentina, BID/INTAL, Fundación Konrad Adenauer, Uruguay, 26-27 setembro 2002, p. 3 (formato paper).

STRECK, Lenio Luiz. Hermenêutica Jurídica e(m) Crise: uma exploração hermenêutica da construção do Direito. 10a . ed. Porto Alegre: Livraria do Advogado, 2010.

TABARÉ, Vasquez y BIZZOZERO, Lincoln. La construcción del MERCOSUR: diagnóstico y evaluación de lo acordado. BID/INTAL, Buenos Aires, 1994. 
Para publicar na Revista de Direito Internacional, acesse o endereço eletrônico www.rdi.uniceub.br ou www.brazilianjournal.org.

Observe as normas de publicação, para facilitar e agilizar o trabalho de edição. 